J Neurol Neurosurg Psychiatry 2005;76(Suppl III):iii48-iii63. doi: 10.1136/jnnp.2005.075226

E ndovascular treatment for cerebrovascular disease has undergone major developments over the last 15 years. Its dramatic evolution has secured its primary role in the treatment of many conditions (intracranial aneurysms, a proportion of venous sinus thrombosis, some arteriovenous malformations, and many dural fistulas), as an effective alternative to surgery in those with pre-morbid medical conditions (carotid angioplasty and stenting), and as a valuable adjunct to neurosurgery (arteriovenous malformations, some complex giant aneurysms, and skull base tumours). Its current place in hyperacute stroke or idiopathic intracranial hypertension is yet to be defined.

Spinal intervention is also evolving (but is not discussed here).

Neurovascular disease should be managed collectively by a multidisciplinary team comprising an interventional neuroradiologist in conjunction with a neurosurgeon (preferably one with a vascular interest) or head and neck surgeon and/or neurologist as appropriate. Neuropsychological assessment both before and after therapy is desirable to document fully and accurately the efficacy of treatment.

\title{
CEREBRAL ANEURYSMS
}

Cerebral aneurysms may present with subarachnoid haemorrhage (SAH) (incidence 6-8 per 100000 in most western populations), mass effect or are discovered incidentally. Diagnosis is achieved using computed tomographic (CT) angiography or magnetic resonance (MR) angiography, but the gold standard in most centres is still digital subtraction angiography. Two methods of treatment are available-neurosurgery and, since the introduction of the platinum Guglielimi (electrolytically) detachable coil (GDC) in 1990, endovascular treatment.

The international subarachnoid aneurysm trial (ISAT), ${ }^{12}$ the only prospective large scale international randomised controlled trial (RCT) comparing neurosurgery with endovascular treatment of ruptured aneurysms, demonstrated a $24 \%$ relative and $7.4 \%$ absolute reduction of death or dependency at one year in favour of coiling.

Patients are treated usually under general anaesthesia and are systemically heparinised during the procedure. A 6 or 7 French guide catheter is introduced via the femoral artery into the internal carotid artery (ICA) or vertebral artery. A microcatheter is advanced over a microguidewire coaxially through the guide catheter into the aneurysm and a series of soft platinum coils (MR compatible) are deployed sequentially until aneurysm occlusion is achieved (fig 1). Heparinisation post-procedure is variable. Most patients receive $75 \mathrm{mg}$ aspirin for three months afterwards to avoid thromboembolic events. Although these mostly occur within the first two days following the procedure, some are reported as late as nine weeks.

Overall procedure related morbidity is $9-10 \%$, and mortality $1-2 \%$. Procedural complications include aneurysm rupture (2-5\%) which may not affect the patient adversely, or may result in a poorer outcome or death. Symptomatic thromboembolic events range from 5-9\%, parent vessel occlusion $2.5 \%$, and coil migration $0.5 \%$. Serious groin haematomas $(0.6 \%)$ may very occasionally require transfusion and, very rarely, surgical repair. (These may also complicate other neurointerventional procedures.)

Aneurysm occlusion relates to the size of aneurysm and its neck. Larger aneurysms with wide necks are more difficult to occlude completely. In ISAT, ${ }^{2} 66 \%$ of aneurysms were completely occluded at follow up, $26 \%$ were subtotally occluded (neck remnant), and $8 \%$ were incompletely occluded. However, most aneurysms bleed from the dome or body and only $2 \%$ from the neck, and it seems logical that a small stable neck remnant is safe. Neurosurgical clipping does not

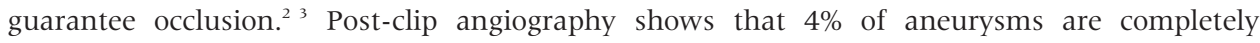
unclipped and another $4 \%$ show major remnants.

Interval post-embolisation angiographic (contrast or magnetic resonance angiography (MRA)) follow up is almost always performed; at the author's institution, at least three years of aneurysm angiographic stability is required in most before the final discharge. 

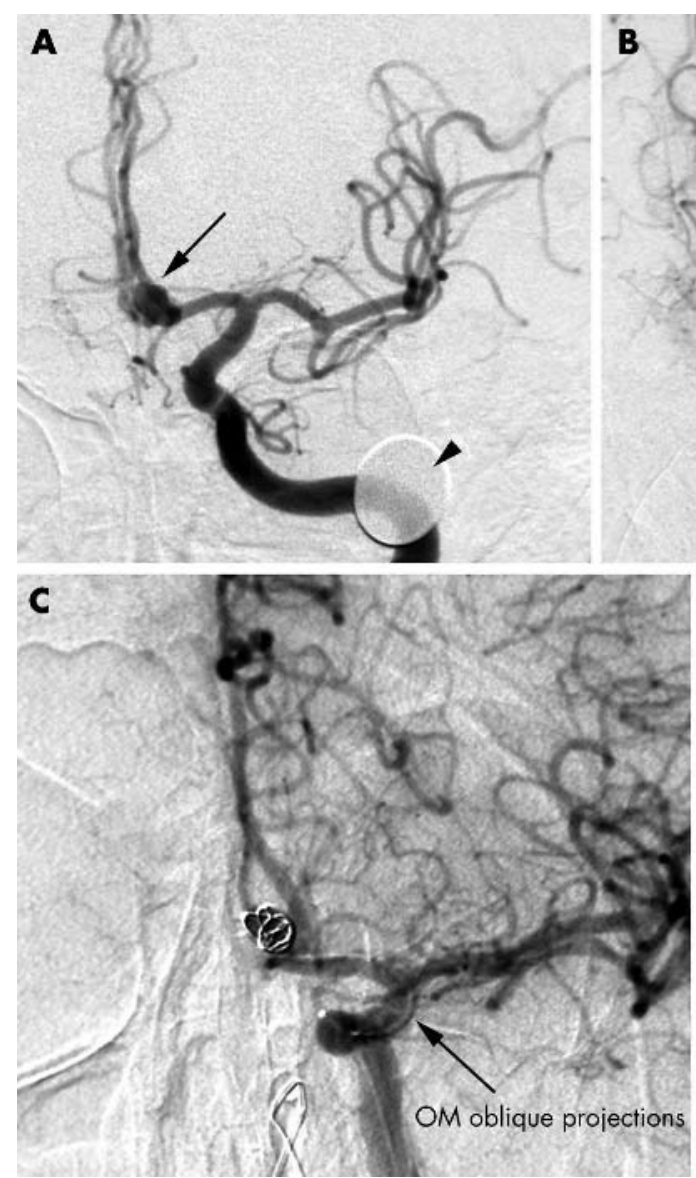
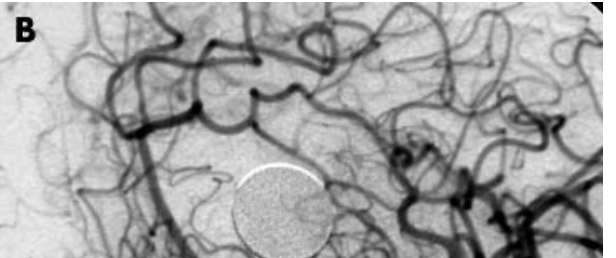

政
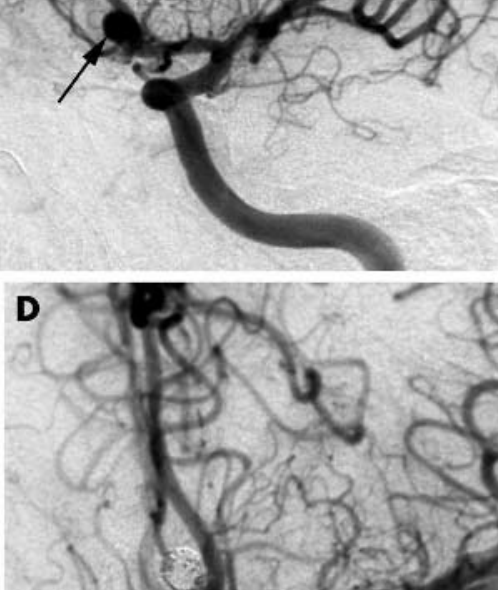

w.

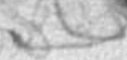

Figure 1 Coil embolisation of an anterior communicating artery aneurysm (A-D). Presented with subarachnoid haemorrhage (SAH) World Federation of Neurological Surgeons (WFNS) grade 1. Left internal carotid artery (ICA) Towne's (A) and occipitomental (OM) oblique (B) angiographic projections of a left ICA angiogram demonstrate a 5-6 mm anterior communicating artery aneurysm (arrow). The coin (a known size) enables accurate sizing of the aneurysm so that the appropriate coils are selected. Leff ICA angiography following deployment of the first coil into the aneurysm (C) shows a satisfactory appearance with coil loops forming a basket around the aneurysm dome and crossing the neck. The microcatheter passing up the ICA into the aneurysm is indicated (long arrow). Several coils are deployed sequentially without complication, achieving satisfactory occlusion as confirmed angiographically (D). The patient made a good recovery from her SAH and the six month check angiography confirmed continued aneurysm occlusion.

Aneurysm recanalisation may occur because the aneurysm lumen is only partially filled with coils-a completely occluded aneurysm contains $25-35 \%$ of its volume with coils, the rest is thrombus. The body's natural thrombolytic processes and coil compaction, more likely in a wide neck, may cause this recanalisation and it is estimated that about $10 \%$ of coiled aneurysms will require a second treatment to ensure stability. The risk of rebleeding has been documented at $0.2 \%$ per patient year with a follow up of $1-8$ years (mean 4 years). ${ }^{2}$ This is similar to the rebleed rate after neurosurgical clipping.

The risk of epilepsy is significantly lower after endovascular treatment. Craniotomy carries a risk of seizures. The relative risk reduction at one year for coiling is $47.9 \%$, and the absolute risk reduction is $3.9 \%{ }^{2}$

Neuropsychology in ISAT is awaited with interest. In one case matched study, neuropsychological outcome tended to be poorer in the neurosurgical group. ${ }^{4}$

Health economic data generated by ISAT is interesting. Although coils are undoubtedly expensive, because of shorter hospital stays, less requirement for rehabilitation, and fewer dependent survivors, endovascular treatment is cheaper.

Since ISAT, there have been many modifications in device technology aiming to achieve safer, more durable treatment of a larger proportion of aneurysms, particularly those with a relatively wide neck where more complete occlusion is more difficult and coil compaction and recanalisation more common. These include: coils with more complex shapes; balloon remodelling (a non-detachable balloon catheter is deployed across the aneurysm neck and the balloon inflated when the coils are deployed in the aneurysm, so preventing prolapse into the parent vessel and allowing tighter packing); stent assisted coil embolisation (fig 2); bioactive coils (coated with polyglycolic polylactic acid to enhance thrombus formation and organisation); hydrogel coils (platinum coils coated with a polymeric hydrogel that swells when in contact with blood, occupying more space within the aneurysm and achieving greater packing density, to reduce recurrence rates and also stimulate a healing cellular response); and radioactive coils (implanted with P32 emitting $\beta$ radiation-local $\beta$ emission can prevent recanalisation by an unknown mechanism). Some trials are underway or are being designed to test efficacy in some of these developments.

The decision to treat ruptured or symptomatic aneurysms is very straightforward. The management of small incidental unruptured aneurysms is more controversial and will depend upon size $(>7 \mathrm{~mm})$, location (posterior communicating artery and posterior circulation aneurysms are more prone to rupture), previous $\mathrm{SAH}^{5}$ and, importantly, the patient's age, life expectancy, co-morbidity, and, of course, wishes (see National Institute for Health and Clinical Excellence (NICE) guidelines). Anterior circulation aneurysms, $<7 \mathrm{~mm}$ in size and in those without prior SAH and with no family history, should probably not be treated.

In the ISUIA study, ${ }^{5}$ the combined mortality and morbidity at one year was $12.6 \%$ for clipping and $9.8 \%$ for coiling for group 1 patients (no previous SAH), a $22.2 \%$ relative risk reduction for coiling. For group 2 patients (previous SAH from another aneurysm) the relative risk reduction for coiling at one year was $29.7 \%$. 


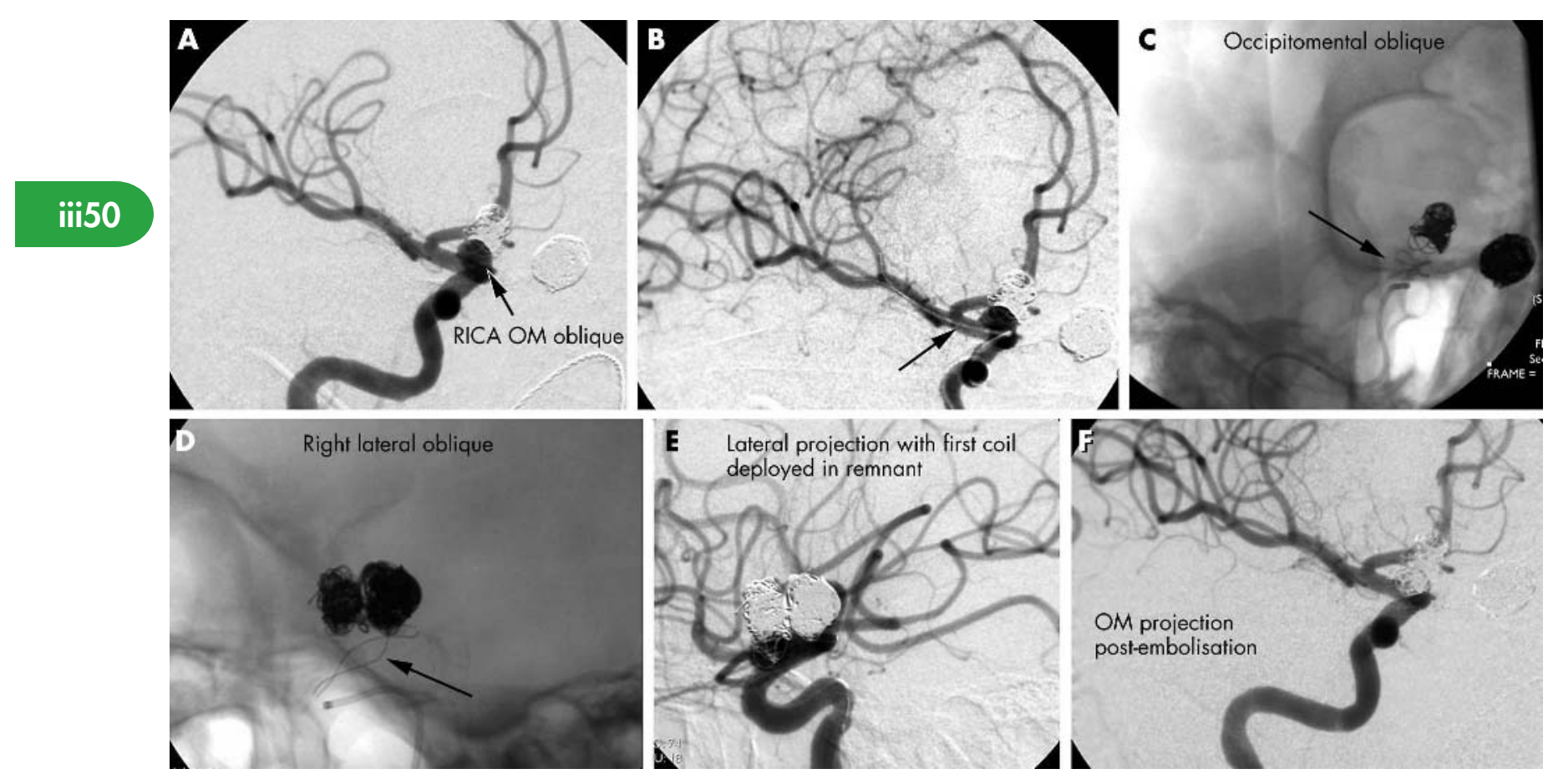

Figure 2 Stent assisted coil embolisation of an aneurysm remnant (A-F). Patient with a grade 1 SAH from an 11 mm right ophthalmic artery aneurysm. This was successfully coiled using the balloon remodelling technique (not shown here) with excellent recovery. A mirror image left ophthalmic aneurysm was coiled three months later (risk of rupture according to ISUIA (international study of unruptured intracranial aneurysms) data is $0.5 \%$ per annum). Unfortunately, coil compaction of the right sided aneurysm occurred (a feature of aneurysm size, location and neck size) and stent assisted coil embolisation of the remnant was performed. Right ICA OM oblique angiographic projections (A) demonstrates a partially occluded ophthalmic aneurysm with a significant remnant (long arrow). A stent delivery microcatheter (short arrow) is deployed across the aneurysm neck (B). (C, D) Fluoroscopy images show the self expandable stent (magnetic resonance (MR) compatible) deployed through this and positioned across the aneurysm neck (arrows). A microcatheter is then manipulated through the stent mesh into the aneurysm remnant and coils deployed sequentially occluding the remnant $(E, F)$.

Meta-analyses comparing the risks of endovascular and surgical treatment for unruptured aneurysms also favour endovascular treatment..$^{6-8}$

These studies have shown that endovascular treatment of unruptured aneurysms is associated with less risk of adverse events (18.5-25\% $\vee 10-10.6 \%)^{6}$ and in-hospital death $(2.3-$ $3.5 \% \vee 0.4-0.5 \%)$, and lower hospital charges and shorter stays compared with surgery. ${ }^{78}$ Operated patients also take longer to recover after discharge.

\section{GIANT ANEURYSMS}

Giant aneurysms are often (but not invariably) suboptimally treated using coils alone. The accepted treatment for many giant internal carotid and vertebrobasilar aneurysms is still parent vessel occlusion.

Trial balloon occlusion (TBO) of the ICA is first recommended to determine whether the patient will safely tolerate permanent occlusion. The risk of neurologic ischaemic deficit following abrupt carotid occlusion in unselected patients is $49 \%$ for ICA occlusion and $28 \%$ for common carotid artery (CCA) occlusion. ${ }^{9}$

The TBO procedure is performed via a transfemoral approach in an awake, sedated, heparinised patient. A double lumen balloon catheter system, either 5 or 7 French, is one of the safest and most reliable. It consists of a permanently mounted balloon and a patent lumen which perfuses the vessel distal to the balloon with heparinised saline, without a standing column of blood and so minimises the risk of distal thromboembolism. The balloon is placed in the proximal ICA and inflated slowly (fig 3D), occluding the artery. The patient is assessed neurologically at intervals for up to 30 minutes. The balloon is then deflated or sooner if the patient experiences a deficit. During the period of balloon inflation, contralateral ICA angiography (fig 3E), via the other femoral artery, may be performed to demonstrate cross flow across the anterior communicating artery and, more important, assessment of the ipsilateral venous phase. A delay of two seconds or more in the appearance of the cerebral veins on the occluded side is evidence of inadequate perfusion by collaterals.

TBO itself is associated with $0.4 \%$ incidence of permanent neurological deficit and no mortality. ${ }^{10}$ This complication rate is similar to diagnostic cerebral angiography.

Vasomotor reactivity and collateralisation are important mechanisms for clinical tolerance. A decline in cerebral blood flow due to decreased perfusion pressure causes resistance vessels to dilate, but once this capacity is exhausted, there is risk of ischaemia with additional hypoperfusion that might be encountered with periods of hypotension, anaemia, hypoxaemia or hypoglycaemia. Approximately $10 \%$ of patients will develop symptoms actually during occlusion. ${ }^{11-13}$ Up to $20 \%$ of those who tolerate temporary occlusion clinically will develop infarction after permanent occlusion. ${ }^{14}{ }^{15}$ In $20 \%$ of these the onset may be after 48 hours, sometimes two weeks later. ${ }^{16}$ Hence, in addition to clinical assessment, a variety of tests may be performed in order to predict those at risk of delayed stroke. These tests include single photon emission computed tomography (SPECT) using 99 mTc hexamethylpropylene-amine oxime (HMPAO) or xenon-133, transcranial Doppler studies, and stable xenon 

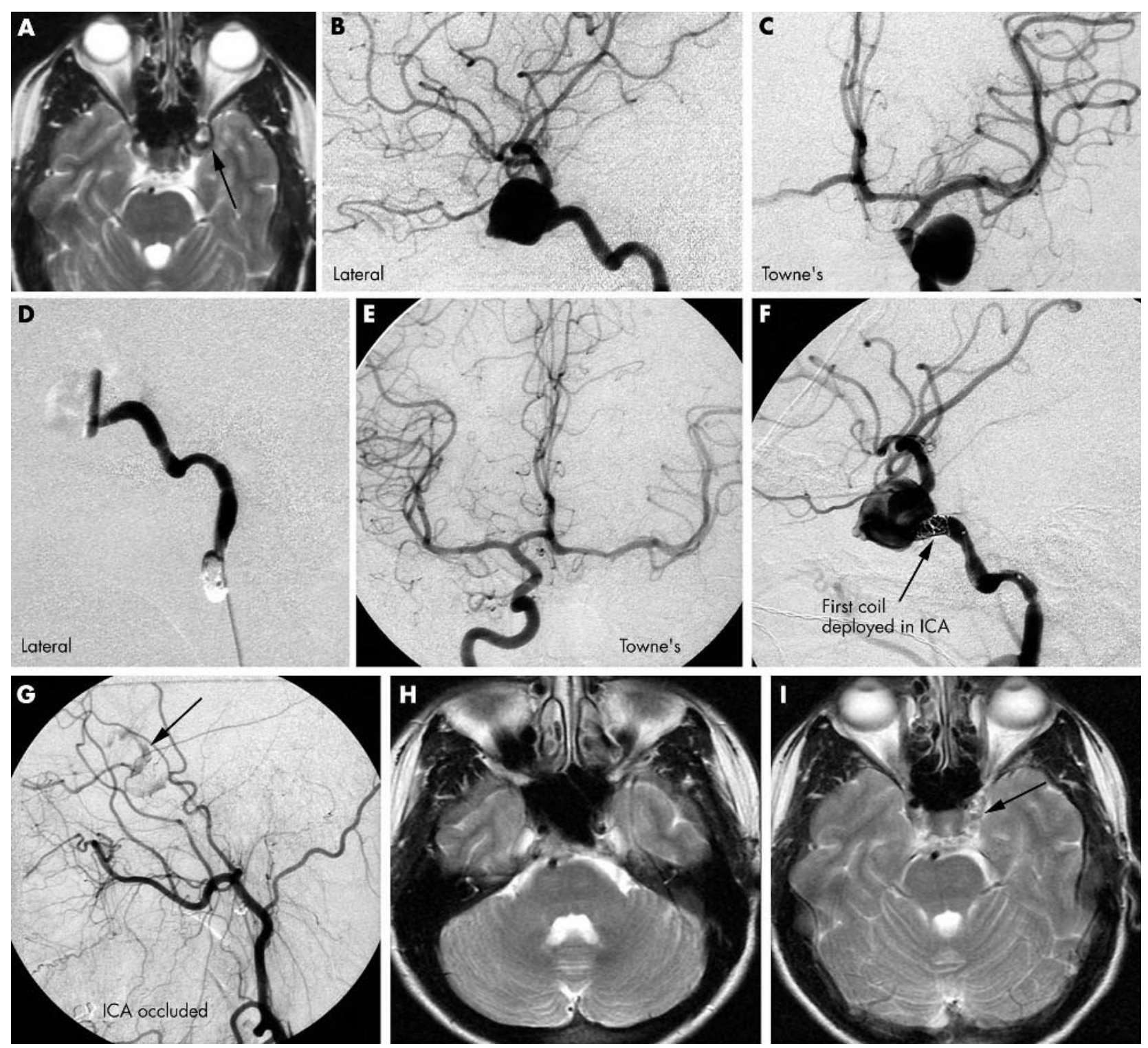

Figure 3 Parent vessel (left ICA) occlusion in the management of a giant cavernous carotid aneurysm (A-H). Patient presented with a left sided 3rd nerve palsy. T2W axial cranial magnetic resonance imaging (MRI) (A) showed that the cause was a giant left sided cavernous aneurysm (arrow). Left ICA angiography $(B, C)$ confirmed the presence of the giant cavernous aneurysm. Parent vessel occlusion was considered the most appropriate treatment and so a trial balloon occlusion ( $D$ and $E$ ) with single photon emission computed tomography (SPECT) was performed. A lateral ICA angiogram demonstrates the non-detachable balloon inflated in and occluding the left ICA (D). Patient remained neurologically intact for the 30 minute period of balloon inflation. Towne's right ICA angiography $(E)$ during this time demonstrated excellent cross flow in the anterior communicating artery with perfusion of the left cerebral hemisphere and no delay in the venous phase. SPECT (not shown) also demonstrated no perfusion deficit. The left ICA was therefore occluded using coils (F, G). Note some faint opacification of the distal left ICA (G, arrow) via ethmoidal arterial collaterals (from the sphenopalatine branch of the internal maxillary artery) to the ophthalmic artery. The third nerve palsy resolved completely within days. Interval cranial T2W MRI axial images $(\mathrm{H}, \mathrm{I})$ demonstrate sustained left ICA and aneurysm occlusion and shrinkage (arrow).

enhanced CT. None is perfect and each technique has advantages and disadvantages. Although they have reduced the delayed stroke rate to 3-8\%, ${ }^{12-14}{ }^{17-22}$ not only can they not predict embolic stroke, they may also fail to identify patients with limited reserve. TBO with hypotensive challenge, reducing mean arterial pressure to two thirds baseline, has been described to identify this group. ${ }^{11}{ }^{16}$ The incidence of false positives from hypotensive challenge is not known and relying on hypotensive challenge may mean that some patients are undergoing unnecessary bypass procedures. These, however, in experienced hands carry a low complication rate.
In the author's experience, SPECT using 99 m Tc HMPAO has proved a reliable technique. Permanent balloon occlusion without revascularisation procedures is not performed in our institution if perfusion defects occurring as a result of occlusion are demonstrated.

Following a successful TBO, the patient may go on to permanent ICA occlusion using detachable balloons or coils (fig 3F, G).

Aneurysm formation de novo occurring as a late complication associated with carotid ligation has been described ${ }^{23} 24$ with a reported incidence between $4-10 \% .{ }^{24}$ The cause is presumably haemodynamic due to increased blood flow. 
Some of these flow aneurysms have been shown to grow and/ or rupture..$^{25-27}$ De novo aneurysm formation and rupture complicating carotid balloon occlusion has also been reported $^{28}$; consequently, some consider the presence of a contralateral aneurysm a contraindication to parent vessel occlusion. ${ }^{29}$

iii52 Vertebrobasilar giant aneurysms may be treated by balloon occlusion of one or both vertebral arteries (VAs)..$^{3031}$ Tolerance of bilateral occlusion is dependent upon the patency of the posterior communicating arteries.

When parent vessel occlusion cannot be tolerated, alternative strategies include surgical bypass procedures with parent vessel occlusion or embolisation using high density onyx, optimally in conjunction with a stent (fig 4). High density onyx is a liquid embolic agent very occasionally used in aneurysm treatment. It is an ethylene vinyl copolymer dissolved in dimethyl sulfoxide (DMSO). When the material comes into contact with an aqueous solution, it precipitates and forms a soft spongy polymer cast, initially with an outer layer, remaining semi-liquid centrally. As further material is injected into the cast, it fills the space into which it is injected, then additional material injected breaks out through the outer layer of the existing cast. The material is constrained by placement of a balloon across the aneurysm neck (fig 4). The material solidifies over 10 minutes. There is increasing evidence that high density onyx achieves better and sustained occlusion of large and giant aneurysms (Dr Saru Cerkirge, personnel communication) and more frequently achieves resolution of mass effect than coil embolisation, especially when used with a stent. ${ }^{32}$

\section{ARTERIOVENOUS MALFORMATIONS}

Arteriovenous malformation (AVMs) are a complex conglomerate of abnormal arteries and veins. They lack an intervening capillary bed and there is resultant high flow arteriovenous shunting through one or more fistulae. Intracranial haemorrhage $(\mathrm{ICH})$ is the most common presentation and is usually parenchymal and/or intraventricular rather than purely subarachnoid. The first haemorrhage is associated with 10\% mortality and 30\% morbidity.

Patients may also present with seizures (which are usually easily controlled), neurological deficits caused by steal or venous hypertension, and most are diagnosed before the age of 40. Occasionally, they are discovered incidentally.

Diagnosis is made by CT or MR imaging (MRI) and full haemodynamic evaluation by cerebral angiography. MRI is useful to localise anatomically the malformation and its relation to eloquent cortex. Functional MRI may prove increasingly useful in this respect.

Treatment will depend upon age, presentation, location, and angiographic morphology. The overall lifetime risk of haemorrhage is estimated at $40-42 \%^{33}{ }^{34}$ and the risk of haemorrhage is often quoted as $2-4 \%$ per year, but this is probably an oversimplification. AVMs are a heterogeneous group and the haemorrhagic risk depends upon previous haemorrhage ( $6 \%$ up to possibly $18 \%$ in the first year after haemorrhage $\left.\mathrm{e}^{35}\right)$. Other quoted risk factors include a diffuse nidus, a single draining vein, deep location with deep inaccessible feeders, perforator supply, deep venous drainage, vertebrobasilar feeders, intranidal aneurysms, small size, and increasing age. ${ }^{36} 37$ The lowest annual haemorrhagic risk is probably around $1 \%$ and the highest may approach $10 \%$.
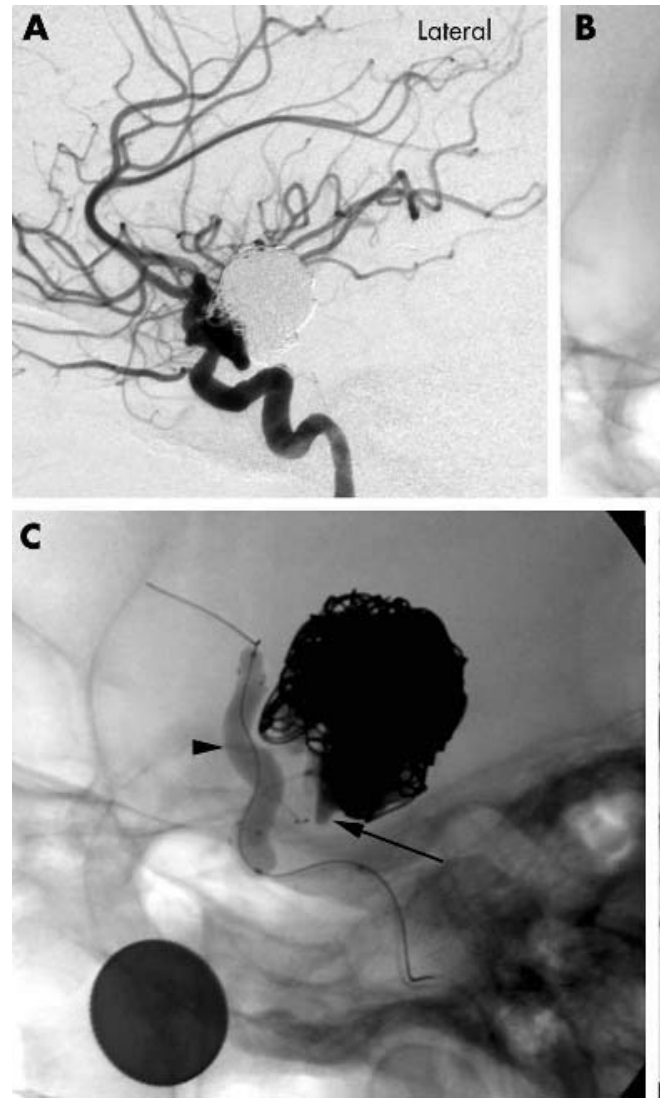
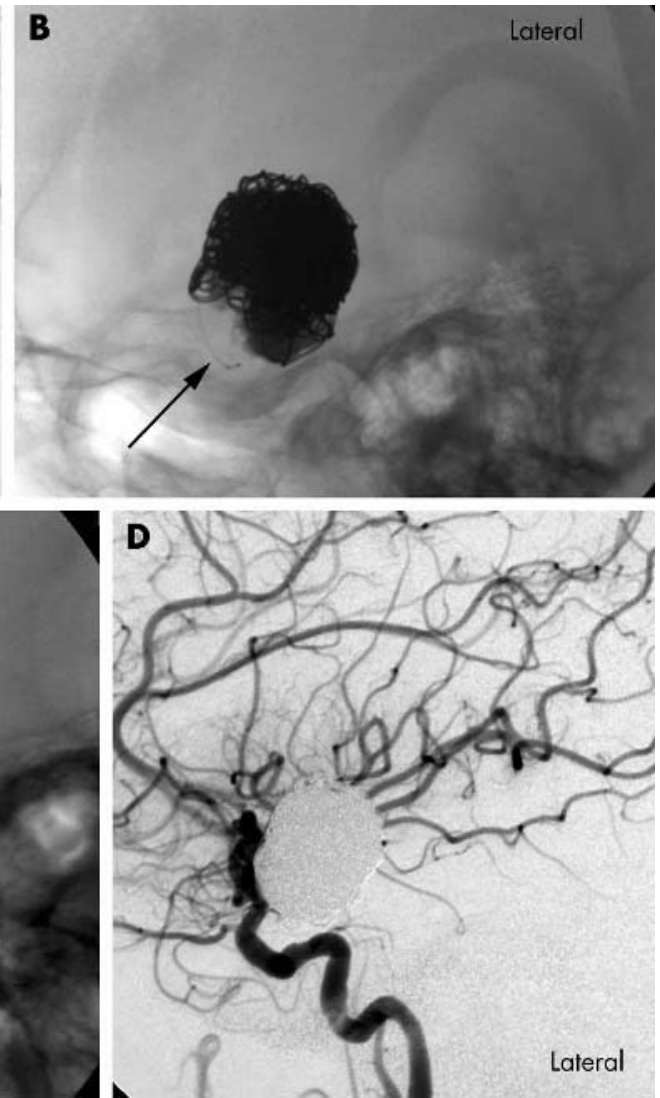

Figure 4 Stent assisted onyx embolisation of a giant posterior communicating artery aneurysm remnant $(A-D)$. A giant posterior communication artery aneurysm was found in a patient investigated for headaches. Trial balloon occlusion of the left ICA showed that the aneurysm filled via collaterals and parent vessel occlusion was not performed. The aneurysm was treated twice with coils and once with high density onyx but still recurred following compaction of the embolic materials, as seen on the lateral left ICA angiographic projection (A). A self expandable stent (different manufacturer to that in fig 3) was therefore deployed across the aneurysm neck ( $B$, arrow), a microcatheter deployed through the stent mesh and injections of high density onyx made into the remnant ( $C$, arrow) using a balloon inflated (arrowhead) across the aneurysm neck (C) to retain the onyx within the aneurysm. Aneurysm occlusion was achieved (D) without permanent complication and follow up angiography one year later confirmed continued occlusion. 
Therapeutic options include neurosurgery, embolisation and stereotactic radiosurgery, in any combination, or no treatment at all if the risks of treatment are considered worse than the natural history. The aim of treatment usually is to obliterate the AVM completely, to eliminate the risk of haemorrhage, and less frequently to reduce the effects of steal or venous congestion.

Partial treatment may alter the haemodynamics and actually increase the risk of haemorrhage. Additionally, recanalisation may occur in incompletely obliterated lesions and other feeders may be recruited. Targeted partial treatment is occasionally considered however, where complete eradication may not be possible, to obliterate an intranidal aneurysm to reduce the risk of bleeding or to reduce the effects of steal.

The Spetzler Martin grading system (grade 1-5) reflects the degree of surgical difficulty and risk of surgical morbidity and mortality, and the scale is based upon AVM size, venous drainage, and location.

Classically, surgery may be recommended in grades 1 and 2 and some grade 3 depending upon location. In these, the surgical risks are low (up to 5\% mortality and morbidity). In those grade 3 AVMs with deep inaccessible feeders, surgery with embolisation or stereotactic radiosurgery is considered.

The management of grade 4 and 5 AVMs is usually multidisciplinary where the surgical risks of a poor outcome are $15-22 \%$.

Endovascular embolisation as a sole treatment has in the past been curative only in a small percentage (5-20\%) of AVMs. ${ }^{38-40}$ These are usually small or moderate in size with only a few feeders and the main role of embolisation is to reduce the size to enable stereotactic radiosurgery (fig 5) or as an adjunct to surgery in larger AVMs. As a presurgical adjunct embolisation actually makes surgery feasible, reduces the size of the nidus, may occlude intranidal aneurysms, may occlude surgically inaccessible feeders, reduces operation time, reduces blood loss, and minimises normal perfusion breakthrough bleeding by reducing arteriovenous (AV) shunting more gradually. The latter results from abruptly decreasing AV shunting and increasing flow through the surrounding ischaemic brain where there may be disturbed autoregulation. Embolisation has been considered to improve surgical and radiosurgery cure rates by $25 \%$ and it is highly probable that developing expertise with newer embolic agents (onyx) may result in obliteration of a larger proportion of the AVM (Dr Saru Cerkirge, personnel communication).

Embolisation, however, carries not insignificant risks and these must be considered in overall patient planning.

Embolisation is carried out under general anaesthesia and via the femoral artery. Superselective catheterisation of the feeding arteries is achieved using a microcatheter with or without the aid of a microguidewire. Liquid embolic agents are generally used, either onyx (lower density than is used for aneurysm treatment) or n-butyl cyanoacrylate (NBCA).

Onyx is mechanically occlusive but non-adhesive (so there is less risk of actually gluing the arterial catheter), is inert and less inflammatory than NBCA, is soft and compressible, easier to operate, is more controllable and more predictable, allows better surgical handling, and is favoured by the author. Very slow controlled injections allow permeation of the onyx through the various AVM compartments via interconnecting vascular channels.
NBCA undergoes rapid polymerisation and solidification when in contact with blood and is rock hard when set. It incites a strong inflammatory reaction and may result in vessel wall necrosis. Polymerisation can be modified with lipiodol and its optimal use requires extensive operator experience.

The complication rates vary from $3-35 \%$ and are obviously higher for higher grade AVMs which may require multiple embolisations and are located in or close to eloquent cortex. Many are transient but minor permanent deficits occur in $10 \%$, major in $8 \%$, and mortality is around $1-2 \% .^{3438} 40-43$ Complications may be thromboembolic or relate to venous occlusion, arterial perforation, or pressure breakthrough bleeding.

\section{SKULL BASE TUMOURS}

The most common tumours requiring embolisation are meningiomas, angiofibromas, and glomus tumours. (Others that may benefit from embolisation include schwannomas, chordomas, osteogenic tumours, vascular metastases, esthesioneuroblastomas, haemangiopericytomas, fibrosarcomas, plasmacytomas, and rhabdomyosarcomas.)

Here, the objective is the selective obliteration of external carotid artery (ECA) feeders which supply much of the intratumoural vasculature before surgical resection, to reduce operative blood loss and facilitate surgery (fig 6). Preoperative embolisation tends to shorten operative times and periods of convalescence, and is cost effective. ${ }^{44}{ }^{45}$ It is also suggested that the likelihood of tumour recurrence is diminished. Embolisation should be performed 24-72 hours before surgery to allow progressive thrombosis. Treatment may be palliative when surgery is contraindicated because of age or poor health.

The principles and methodology discussed are relevant to embolisation in the ECA territory in general and are applicable to skull base tumours, ECA supply to dural fistulas (DAVFs), and in intractable epistaxis.

The procedure is performed under sedation via the femoral artery. A full angiographic assessment is obtained first. Venous assessment may be important when the tumour is compromising a dural sinus or jugular vein. Superselective catheterisation of individual feeding vascular pedicles is performed (fig 6) using a microcatheter and microguidewire. Pre-embolisation angiography is performed through the microcatheter checking for dangerous anastomoses between ECA and ICA and/or VA branches, and embolisation then performed when safe to do so using an appropriate embolic agent, carefully injected as close to the tumour as possible, under continuous fluoroscopic monitoring. Strict attention must be paid to avoid reflux of embolic material and opening up of dangerous anastomoses. Ideally, the embolic material should pass deep into the vascular tumour bed. Proximal occlusion is inadequate and allows distal collateralisation.

Polyvinyl alcohol particles (PVA) is the most common particulate agent to embolise ECA feeders supplying skull base tumours and DAVFs. A wide variety of particle sizes are available ranging from $45-1000 \mu \mathrm{m}$. They are suspended in contrast medium and injected by hand with careful fluoroscopic monitoring. They are non-resorbable and induce an acute inflammatory reaction in the walls of the embolised artery followed by a giant cell foreign body reaction. Devascularisation, however, is not usually permanent and recanalisation may occur around the particles. The smaller particles achieve the best devascularisation, but when there is 

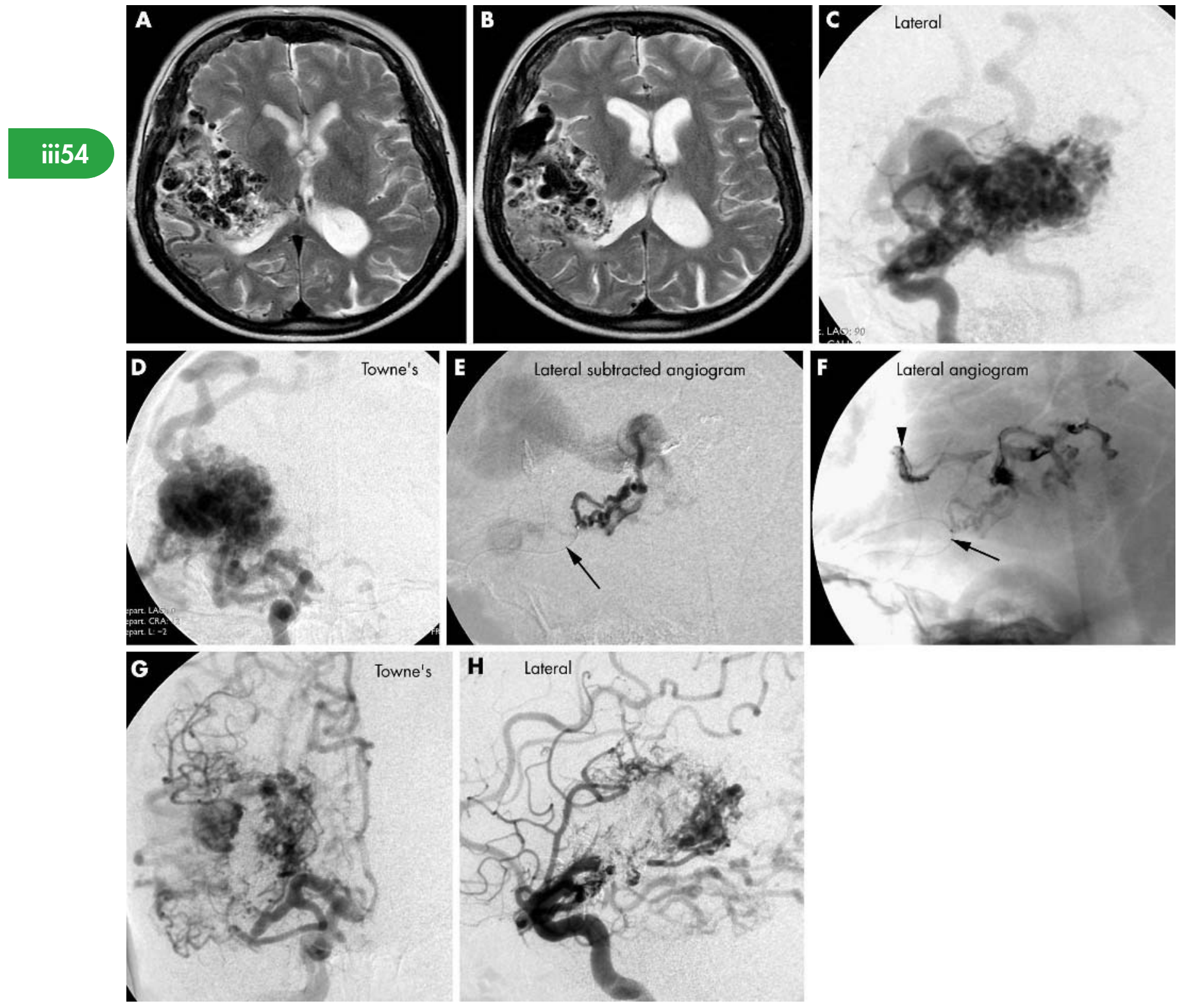

Figure 5 Onyx embolisation of a right perisylvian arteriovenous malformation (AVM) (A-H). A patient presented with a severe intraventricular haemorrhage from a large right sided perisylvian AVM as seen here on T2W axial cranial MRI images (A, B) and right ICA angiogram (C, D). Lateral (C) and Towne's (D) projections demonstrate the arterial feeders arise predominantly from branches of the right middle cerebral artery (MCA) and anterior choroidal artery. Following a good recovery the patient was keen to have the AVM cured for fear of suffering another haemorrhage. Embolisation using onyx was therefore carried out to reduce the size and flow before stereotactic radiosurgery (STRS). The microcatheter ( $E$, arrow) has been navigated to the nidus via an MCA feeder. Selective angiograms via the microcatheter demonstrate that no normal vessels supplying normal brain arise from this feeder at this point and onyx is injected slowly with progressive obliteration of the nidus. Note the onyx caste ( $F$, arrowhead). Towne's $(G)$ and lateral $(H)$ post-embolisation ICA angiograms show that a large proportion of the AVM has been obliterated, but the anterior choroidal supply remains unfortunately. It was impossible to navigate the microcatheter down this vessel to embolise this component safely and the patient was referred for STRS to cure the remnant.

AV shunting, particle size may need to be increased to prevent passage into the venous side and also to avoid dangerous anastomoses and cranial nerve supply. PVA particles $150-250 \mu \mathrm{m}$ are generally preferred by the author, although smaller particles $(50-150 \mu \mathrm{m})$ allow even more distal penetration of the tumour vascular bed and better devascularisation, ${ }^{46}$ but risk devascularising cranial nerves (the vasa nervorum are usually smaller than $150 \mu \mathrm{m}$ ) and skin. Smaller particles may also increase the risk of tumoural swelling and intratumoural haemorrhage. ${ }^{47} 48$ Liquid agents are not often used because of their ability to pass through even tiny anastomoses and occlude cranial nerve arterial supply.

If critical anastomoses are present, particulate embolisation may still be performed if the anastomotic connection is first occluded using coils.

In experienced hands, complications are rare $(0.5-1.6 \%)$ and relate to poor technique, particle reflux, and nonvisualisation of dangerous anastomoses resulting in blindness or irreversible neurological deficits. 

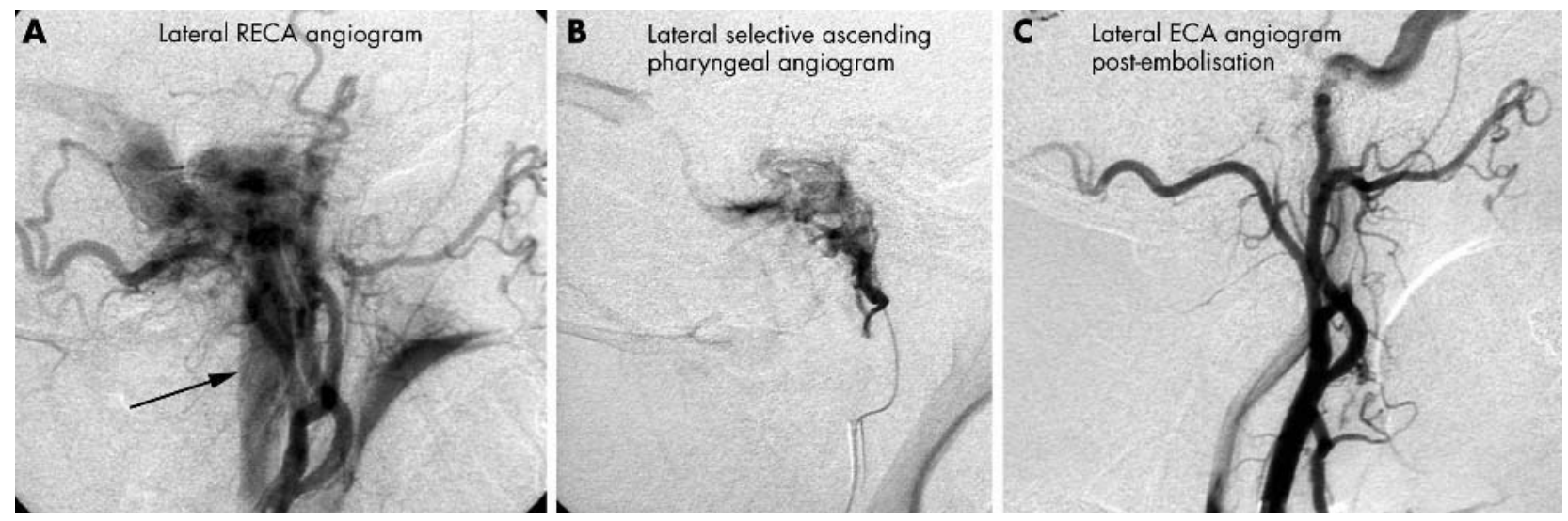

Figure 6 Polyvinyl alcohol (PVA) embolisation of a glomus jugulare tumour (A-C). Patient presented with right pulsatile tinnitus. Cranial MRI and skull base CT (not shown) demonstrated that the cause was a glomus jugulare tumour. Cerebral angiography (A) demonstrated that the supply was arising from occipital and ascending pharyngeal arteries, principally the latter. Note the high vascularity and arteriovenous shunting with early opacification of the jugular vein (arrow). The occipital and ascending pharyngeal arteries (B) were selectively catheterised in turn. Selective angiograms confirmed the absence of dangerous anastomoses with either the ICA or VA, and PVA particles (150-250 $\mu \mathrm{m})$ were injected devascularising the tumour vascular bed (C), three days before surgical excision.

Rarely following embolisation, there may be an acute exacerbation of mass effect caused by tumour swelling or haemorrhage. The patient should therefore be monitored carefully after the procedure in case urgent surgical intervention is required.

Otherwise, the definitive surgery should be delayed for at least 24 hours after the embolisation. The optimal delay is probably 3-5 days and delays of more than one week may be disadvantageous because of recanalisation or collateralisation.

A direct puncture technique has been described to embolise angiofibromas, paragangliomas, haemangiopericytomas preoperatively or as effective palliation for vascular skull vault metastases. ${ }^{49} 50$ This technique is particularly useful if a large tumour blood supply is derived from the internal carotid or ophthalmic arteries when complete preoperative devascularisation using a microcatheter is not possible without unacceptable risk. In these instances, complete preoperative devascularisation may be achieved with minimal risk to the patient by direct tumour puncture and injection of NBCA into the tumour vascular compartment. ${ }^{49} 50$

\section{CAROTID CAVERNOUS FISTULAS}

Carotid cavernous fistulas (CCFs) result from an abnormal connection(s) between the cavernous ICA and venous channels of the cavernous sinus, and are either high or low flow.

Symptoms usually reflect venous hypertension and relate to duration, fistula size, location, and adequacy and route of venous drainage.

Patients with high flow direct fistulae (type A) usually present within days or weeks after head injury, but occasionally onset may be delayed, sometimes for years. Often there is profound venous hypertensive ophthalmopathy, and reflux of blood into cortical veins with cortical venous hypertension, risking ICH. Hemispheric ischaemia may occur secondary to vascular steal.

Most can be treated on an elective basis, but emergency treatment is indicated in the presence of an acute hemiplegia due to steal, herniation of the cavernous sinus into the sphenoid sinus (risk of massive epistaxis), recruitment of cortical venous drainage, and intraocular pressure $>40 \mathrm{~mm} \mathrm{Hg}$ as this is associated with blindness or glaucoma.

Detachable balloons have been the treatment of choice for most type A CCFs until recently because the favoured silicone balloons are no longer available (fig 7). The currently available latex balloon is deployed up the ICA, through the defect and inflated within the cavernous sinus, occluding the fistula in $90-99 \%$ and preserving the ICA in $88 \% .^{51-53}$ The permanent neurological complication rate is $4 \% .^{54}$ Alternatively, coils or onyx can be deployed through the microcatheter into the cavernous sinus, with balloon protection (non-detachable) in the ICA.

The arterial route to the cavernous sinus, via the ICA, is successful in most traumatic CCF. In the others, a transvenous route through the inferior petrosal sinus, superior petrosal sinus, or superior ophthalmic vein (SOV) are alternate routes, using coils to occlude the cavernous sinus. The SOV may be accessed via the facial vein which connects with the SOV and internal jugular vein. Failing this, a surgeon can dissect out and catheterise the vein in the operating theatre.

The outcome from management of type A CCF is usually excellent..$^{53}$ The patient's proptosis rapidly regresses and the eye may be completely normal one week later.

In low flow indirect dural fistulas (type B), presentation is less acute and symptoms and signs may be both non-specific and subtle. They may complain of retro-orbital headaches due to stretching of dural lining of the distended cavernous sinus or spontaneous thrombosis at the fistula site or draining veins.

Most type B CCFs are associated with low morbidity and up to $50 \%$ may spontaneously resolve. Since they do not usually produce major neurological deficits and are not life threatening, a minimally invasive form of therapy is desirable. Treatment should be focused on the patient's symptoms and not necessarily complete angiographic cure.

Treatment is indicated when ophthalmic symptoms are severe and/or progressive. Prompt treatment is required when there is a severe or progressive orbital and intracranial venous 


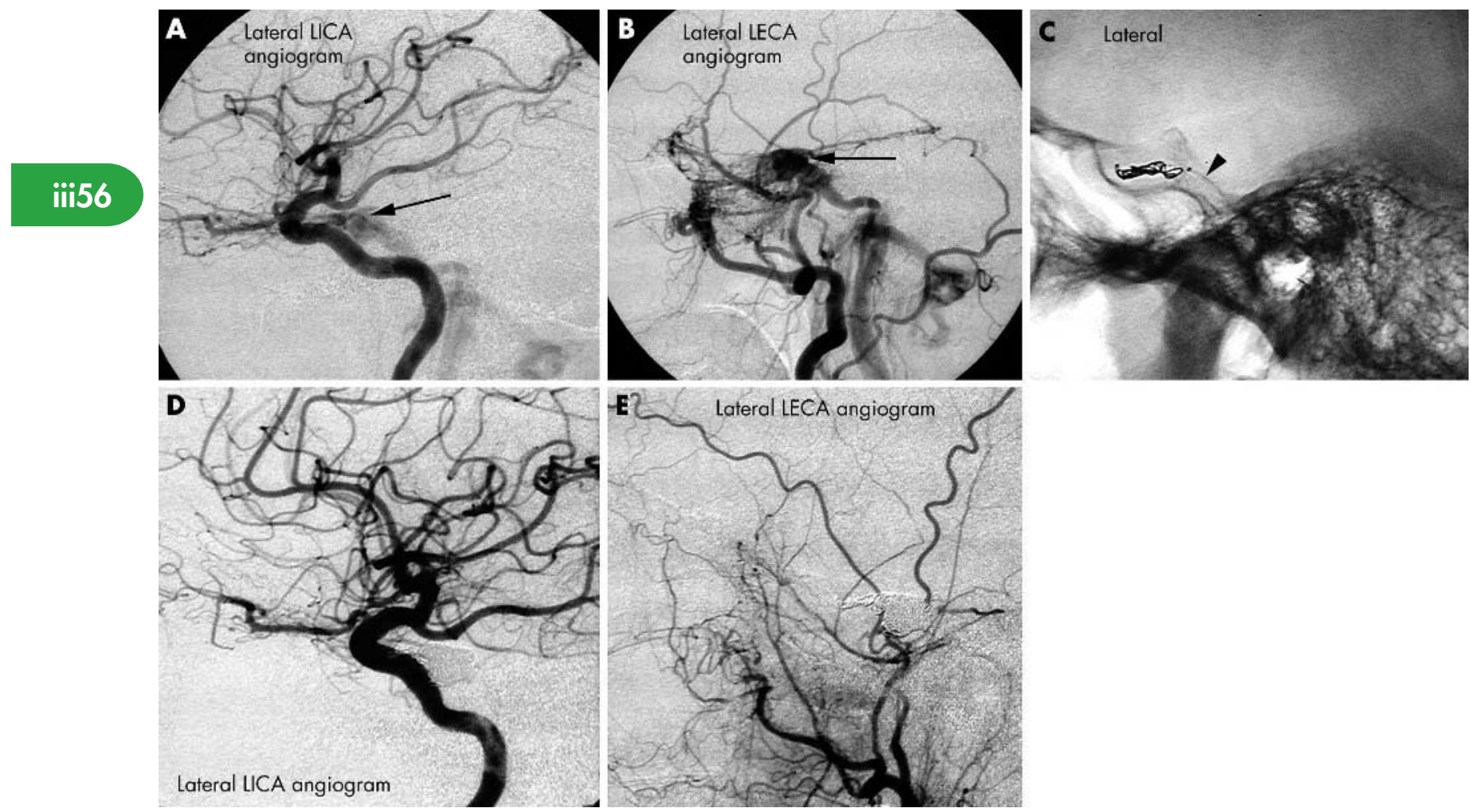

Figure 7 Transvenous embolisation of a caroticocavernous dural fistula (CCF) (A-E). Patient presented with pain behind the left eye and a left sixth nerve palsy and cranial MRI (not shown) demonstrated a left dural CCF with venous drainage predominantly posterior and inferior down the inferior petrosal sinus. Cerebral angiography demonstrated that the arterial supply arose from dural branches of the left ophthalmic artery and cavernous ICA (A), middle meningeal artery (MMA), and other small branches of the internal maxillary artery (IMA) (B). At first, the MMA and IMA supply was satisfactorily embolised using PVA particles (not shown), but unfortunately recanalisation rapidly occurred and transvenous coil occlusion of the cavernous sinus was necessary. A guide catheter was retrogradely manipulated to the left jugular bulb via the femoral vein. A microcatheter and wire were navigated through this, up the inferior petrosal sinus to the cavernous sinus ( $C$, arrowhead) and a series of coils sequentially deployed occluding both the cavernous sinus and the fistula $(D, E)$.

congestion. Other indications are relative depending upon the patient's tolerance of bruit and headache.

Carotid-jugular compression involves compression of the ipsilateral common carotid artery with the contralateral hand for 10 seconds per compression, 4-6 times each waking hour. The compression time may be gradually increased to 30 seconds with the neck moderately hyperextended to allow adequate compression, and performed for 4-6 weeks. This procedure should be supervised at first by a clinician to ensure that the patient does not experience a vasovagal attack or cerebral ischaemia. If properly performed it causes simultaneous compression of both the carotid artery and internal jugular vein, so reducing arterial flow and raising venous pressure. Cure may be achievable in approximately $34 \%$ of patients. ${ }^{55}$

This form of treatment is contraindicated in patients with carotid artery atherosclerosis, for fear of embolic events, those with hypercoagulable states, and patients with cortical venous drainage, ICH or visual deterioration in whom more aggressive treatment is indicated.

ECA feeders may be embolised, preferentially using PVA particles, achieving complete cure in $70-78 \%$ and improvement in $20-30 \%$, with a complication rate of $5 \% .^{55-57}$ Recanalisation, however, may occur and in these cases, transvenous coil occlusion of the cavernous sinus either through the jugular vein and inferior petrosal sinus (fig 7) or through the superior ophthalmic vein achieves cure in most patients with a $6 \%$ complication rate. ${ }^{58}$

\section{OTHER DURAL ARTERIOVENOUS FISTULAS}

Dural arteriovenous fistulas (DAVFs-abnormal arteriovenous connections within the dura, usually within the walls of a dural sinus or cortical vein) comprise $10-15 \%$ of all intracranial arteriovenous malformations. ${ }^{59}$ They are probably acquired lesions often occurring as a consequence of venous sinus thrombosis and/or venous hypertension. Thrombosis triggers the stimulation of angiogenesis and engorgement of microscopic arteriovenous channels that normally exist in the dura. The cavernous sinus and transverse sigmoid sinuses are most often implicated, but any sinus may be involved..$^{60}$

The symptoms are variable depending upon location and venous drainage, and the potential risks of DAVFs are directly related to the latter. Cognard's classification ${ }^{61}$ is useful in risk assessment (there are other classifications). Cognard classifies five main types of venous drainage: type I includes DAVFs which drain into a sinus with normal antegrade flow; type II DAVFs drain into a sinus, but there is insufficient antegrade flow because of sinus stenosis/occlusion or high flow, and there is reflux into either venous sinuses (IIa), cortical veins (IIb), or both (IIa+b); type III fistulas drain into cortical veins without venous distension; type IV drain into 
cortical veins with venous ectasia; type $\mathrm{V}$ drain into spinal perimedullary veins.

Types I and IIa comprise just over half of all DAVFs.

Type I DAVFs are benign. Aggressive features are present in about $37 \%$ of type IIa and these relate to elevated intracranial pressure. Patients with type I or type IIa DAVF are not at risk from ICH. ${ }^{61}$

In those with type IIb fistulas, 30\% have aggressive symptoms, with ICH and intracranial hypertension. In type $\mathrm{II} a+b$, aggressive features are present in two thirds, in three quarters of type III, and nearly all of type IV. Half those with perimedullary venous drainage had progressive myelopathy and most of the others had SAH.

Treatment options include no intervention, compressive therapy, endovascular therapy, surgical excision, stereotactic radiosurgery, or a combination. DAVFs with benign features only should not be treated aggressively.

Management of low risk type I fistulas, which often seem to involve the transverse sigmoid sinus, may be conservative. Treatment is indicated if symptoms such as tinnitus are very disturbing and may include carotid or occipital artery compression in the motivated patient. Particulate embolisation of ECA feeders may also relieve symptoms.

Type IIa treatment of choice is arterial embolisation of ECA feeders using PVA particles, repeated as necessary to diminish flow and intracranial hypertension, but this achieves angiographic cure in only a small number. Recanalisation occurs and there is often recruitment of other feeding arteries (fig 8).
In types IIb and IIa+b, suppression of cortical venous reflux is important and may occasionally be achieved by arterial embolisation, but sinus occlusion is usually necessary. ${ }^{62}$ Transvenous coil occlusion of the involved dural sinus by endovascular means can be safely achieved only if it is not involved in the venous drainage of normal brain. Often pressure in the involved sinus is elevated with flow reversal in the veins normally draining towards the sinus. These veins transmit high pressure arterialised blood retrogradely; they may be occluded at their site of origin with the sinus without risk of venous infarction because the brain has already developed collateral venous drainage channels. The sinus is catheterised retrogradely via the jugular vein and occluded using platinum coils, ensuring that the fistula site is actually occluded and not trapped.

If the sinus is thrombosed on both sides of the DAVF, then access may be gained either through the thrombosed portion $^{63}$ or by directly into the isolated portion of the sinus via a small craniotomy. ${ }^{64}$

Types III and IV are very aggressive and partial obliteration will not adequately protect against haemorrhage. The goal of treatment must be complete occlusion. In those where the DAVF drains into a cortical vein, endovascular occlusion of the draining vein itself using coils may occlude the fistula preserving dural sinuses (fig 8).

Although the role of surgery is probably limited now in DAVFs involving the transverse/sigmoid sinuses and cavernous sinus, surgery may have an important role to play in tentorial lesions and anterior cranial fossa and superior

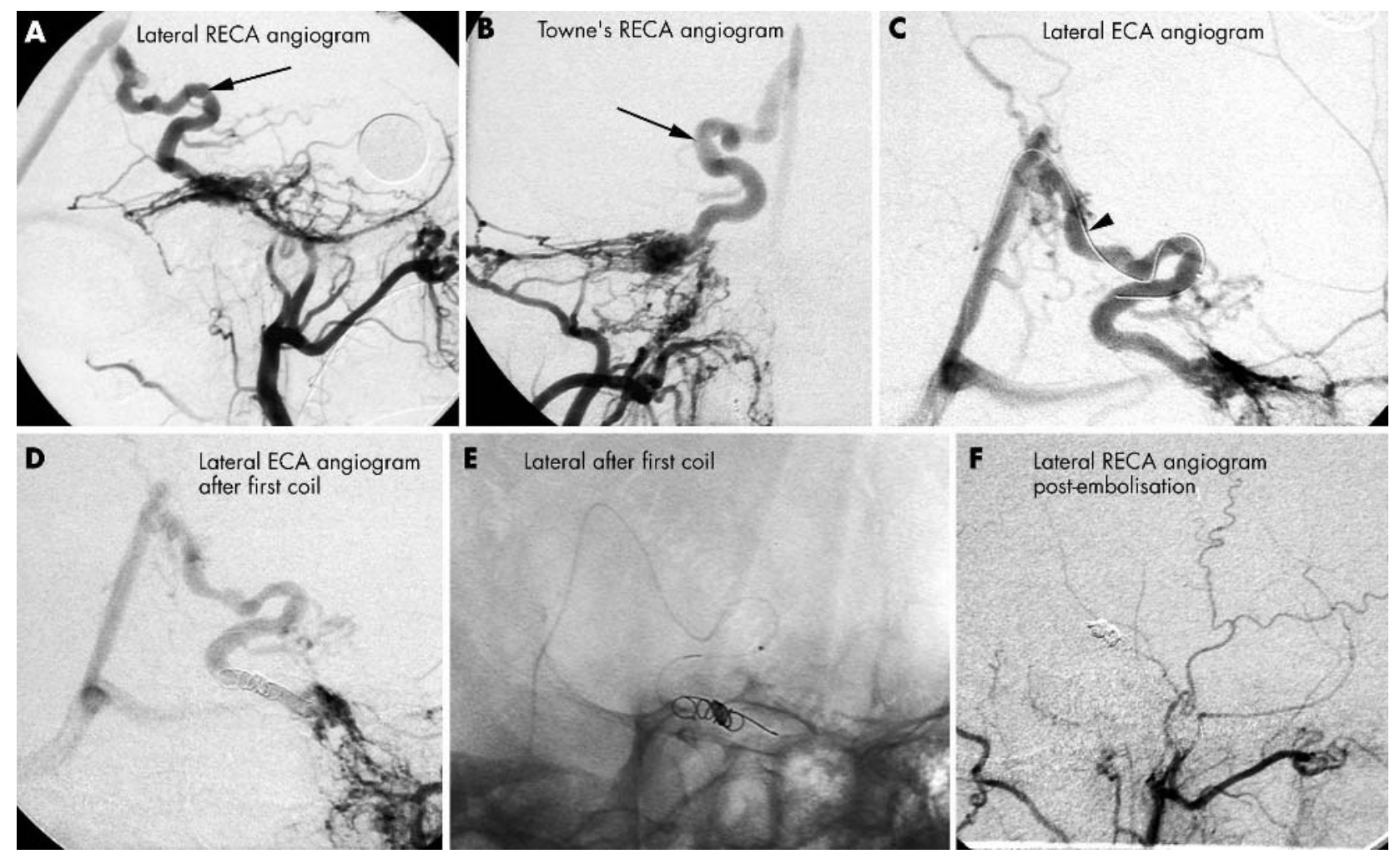

Figure 8 Transvenous coil occlusion of a right sided tentorial Cognard grade IV dural arteriovenous fistula (DAVF) (A-F). Patient presented with headaches. Angiography (A, B) demonstrated a grade IV DAVF located in the right tentorium and supplied predominantly by branches of the right MMA and draining to a dilated mesencephalic vein (arrow). A microcatheter over a wire (arrowhead) was navigated retrogradely transvenously up a guide catheter in the internal jugular vein, and then along the left sigmoid and transverse sinuses, straight sinus, and mesencephalic vein (C) to the site of the fistula. The vein and fistula were occluded at this point using coils (D, E, F). It was safe to occlude the vein because pressure in the vein was high and it was not draining normal brain. 
sagittal sinus DAVFs because their location, arterial supply, and venous drainage is usually not favourable for safe cure by embolisation. Surgery is safer and more effective.

\section{CEREBRAL VENOUS SINUS THROMBOSIS}

Most patients with cerebral venous sinus thrombosis (VST) are successfully treated with anticoagulation. However, some deteriorate despite maximal therapy. In these patients, local thrombolysis has been reported to be effective. There are no trials to date but this would appear to be a promising intervention in selected patients.

Systemic intravenous thrombolytics have been tried with variable success and are not recommended. ${ }^{65-70}$

Pharmacological local thrombolysis is performed at our institution if the patient is in coma at the outset or if there is clinical deterioration despite full anticoagulation. Currently local thrombolysis of the cerebral venous sinuses is usually performed via the transvenous femoral route in an anaesthetised patient (fig 9). The patient is already anticoagulated. The objective in most cases is complete recanalisation but while this is desirable, our experience suggests that complete recanalisation is not always necessary for a good outcome. Heparin is usually continued post-procedure and the patient subsequently receives warfarin. Pharmacomechanical thrombolysis, which increases the surface area of thrombus exposed to thrombolytic agent, may also be achieved using a balloon catheter ${ }^{71-73}$ or microsnare ${ }^{73}$ device. The latter is a microcatheter with a wire loop at the end which can be extruded and retracted back into the catheter, so macerating the thrombus. The technique may be painful and theoretically increases the risk of the procedure as perforation of the sinus could be catastrophic. Clot maceration has been shown to decrease the time required for thrombolysis by $50 \%$.

Local pharmacological thrombolysis is not always successful and older emboli/clots are much more difficult to lyse compared with "fresh" ones. ${ }^{74}$

ICH with clinical worsening has been reported in two patients. $^{75}$ In both cases the thrombolysis had to be terminated but both patients made a good recovery at one and two months.

Catheter mediated thrombectomy using a saline jet vacuum device has also been described and is used together with local pharmacological thrombolysis. ${ }^{76-81}$ This device was originally marketed in the treatment of thrombosed dialysis grafts and has also been used in coronary thrombectomy. A clinical trial to evaluate its use in carotid artery occlusion is currently underway. It consists of a double lumen 5 French catheter tapering to 3.5 French, and its size alone creates potential difficulty in navigating the catheter to the site of thrombus. Navigation of the catheter may not be accomplished in all venous sinuses, ${ }^{80}$ but perhaps access may improve with the development of smaller devices. Once in place, high velocity saline jets, exiting the catheter at a pressure of $2500 \mathrm{psi}$, are directed through one lumen, connected to a bag of heparinised saline. A venturi effect breaks up the thrombus and the debris is directed down the other lumen and collected in a bag. This device theoretically has the advantage of eliminating larger volumes of thrombus more quickly but preclinical evaluation suggests that it can result in mild focal injury to blood vessels. It should probably be reserved for those with extensive thrombosis and malignant intracranial hypertension who would benefit from more rapid clearing of thrombus and with those where there is failure of routine local thrombolysis.

There are two case reports of successful venous sinus angioplasty and stenting in two patients with progressive cognitive decline caused by VST complicated by DAVF and venous hypertension. ${ }^{82} 83$

\section{CAROTID ANGIOPLASTY AND STENTING}

Carotid endartectomy (CEA) is currently the preferred method for treating symptomatic and asymptomatic patients with high grade extracranial stenoses if the perioperative stroke and death rate is $6 \%$ or less in symptomatic patients and $3 \%$ or less in asymptomatic ones. The major risks associated with CEA are ischaemic stroke, ICH, myocardial ischaemia/infarction, heart failure, neck haematomas, and cranial nerve injury.

In experienced hands, carotid angioplasty and stenting (CAS) is probably as safe and effective as CEA. In the "real world", complication rates of CEA are significantly higher than the trials suggest ${ }^{84}$ and in the endartectomy trials, high risk patients were excluded.

Patients undergoing CAS are pre-treated with antiplatelet agents and the procedure itself is performed under local anaesthesia via the femoral artery. The patient is systemically
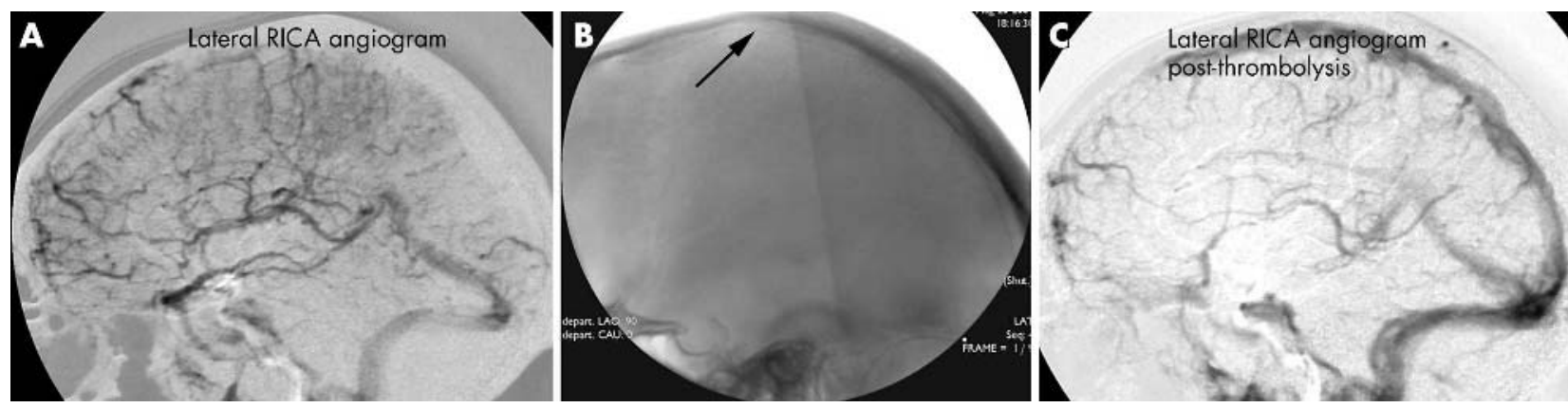

Figure 9 Local pharmacomechanical thrombolysis in superior sagittal sinus (SSS) thrombosis (A-C). Patient experienced two focal left sided seizures followed by progressive fall in Glasgow coma scale over the next few hours. The diagnosis of SSS thrombosis was made on admission cranial CT scan. As a result of the rapidly declining clinical state, thrombolysis was performed. Right ICA angiography confirmed the diagnosis of isolated SSS thrombosis. Via the femoral vein a guide catheter was navigated back up to the right jugular bulb and a microcatheter (arrow-lateral skull view, B) and microguidewire were placed retrogradely up through this, through the sigmoid and transverse sinuses, and up through the thrombosed SSS Hand injection of recombinant tissue plasminogen activator (rt-PA) was made along the thrombosed sinus and the clot was macerated using the microcatheter and microguidewire. Ninety minutes later, the sinus was largely recanalised (lateral right ICA angiogram, C). The patient made an excellent rapid clinical recovery. 


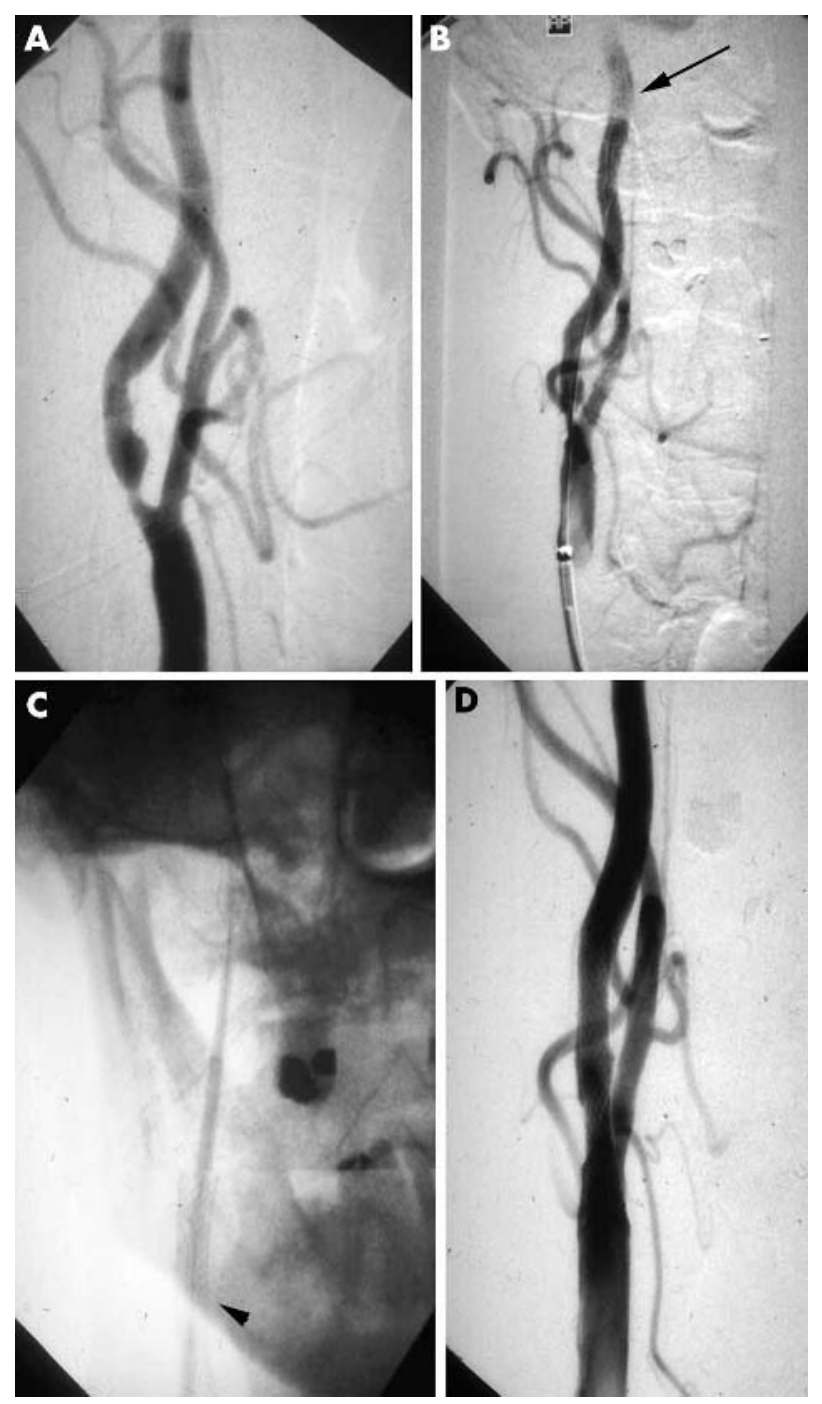

Figure 10 Carotid angioplasty and stenting (A-D). Doppler ultrasound diagnosed a $70 \%$ right carotid bulb stenosis in a patient with right hemisphere transient ischaemic attacks (TIAs). Common carotid angiography $(\mathrm{A})$ confirmed the presence of a tight irregular carotid bulb stenosis. Via a catheter in the common carotid artery (CCA), a guide wire crosses the stenosis, a protection device is deployed (B) (arrow), the stenosis is predilated using an angioplasty balloon, and a stent (arrow) is deployed across the stenosis and redilated (C) achieving an excellent result (D). Figures courtesy of Dr Andy Clifton.

heparinised and the carotid artery catheterised (fig 10). Clopidogrel and aspirin are maintained for three months.

CAVATAS $^{85}$ (carotid and vertebral artery transluminal angioplasty study) was the first prospective RCT comparing CEA with balloon angioplasty \pm stent in highly selected symptomatic patients (504) with high grade stenosis. Only $20 \%$ of endovascular patients had a stent. The 30 day death or disabling stroke rate was $5.9 \%$ for CEA and $6.4 \%$ for endovascular treatment. Any stroke occurred in 10\% of both arms. Local complications were greater with CEA: cranial nerve palsy $(8.7 \% v 0 \%)$ and haematoma requiring surgery or prolonged hospitalisation (6.7\% v 1.2\%). However, the $95 \%$ confidence intervals of each treatment were wide and concerns about endovascular treatment remain. Phase II of this study is ongoing as are other trials (CREST, SPACE, EVA3S) and results are awaited.
Restenosis rates in the CAVATAS patients have been recently reported.$^{86}$ Restenosis to $70 \%$ or more occurred in $18.5 \%$ of the endovascular group at one year in comparison with $5.2 \%$ of the CEA cohort. The results were significantly better after stenting; $15.6 \%$ of the severe restenosis in the endovascular cohort had recurrent transient ischaemic attacks (TIAs). None had fatal or disabling strokes. The restenotic lesion is probably the result of myointimal hyperplasia with a smooth endoluminal surface producing hypoperfusion rather than an ulcerated lesion.

At the time of writing, the latest report from the global carotid artery stent registry ${ }^{87}$ documents 11243 patients undergoing 12392 procedures. The technical success rate is $98.9 \%$, the rate of procedure related transient ischaemic episodes is $3.07 \%$, minor strokes $2.14 \%$, major strokes $1.2 \%$, and procedure related death $0.64 \%$. The stroke and death rate without cerebral protection is $5.29 \%$, and $2.23 \%$ with protection. Restenosis rates of $2.7 \%, 2.6 \%$, and $2.4 \%$ at one, two, and three years are recorded. The rate of neurologic events after stent placement is $1.2 \%, 1.3 \%$, and $1.7 \%$ at one, two, and three years.

The procedural risks relate to lesion morphology as well as operator experience and dexterity. The risks are lower with short $(<1 \mathrm{~cm})$, smooth stenoses $(<85 \%)$. The risk is higher with long $(>2 \mathrm{~cm})$, very ulcerated, $>95 \%$ stenoses, associated with clot formation, with contralateral ICA occlusion or non-functioning anterior or posterior communicating arteries. Some consider polypoid globular lesions are best managed surgically. ${ }^{88}$

Over the years, this registry has noted a progressive decrease in the complication rate-the result of better devices, particularly self expandable stents and cerebral protection devices. The former are associated with far fewer and less severe episodes of transient bradycardias compared with balloon expandable stents. Drug eluting stents and bioactive stents to prevent restenosis are being evaluated.

In conclusion, data so far suggest that CEA and CAS have similar early risks of death or stroke and similar long term benefits, but until awaited RCTs report, CEA is still recommended as the treatment of choice and CAS should be performed only in an ongoing trial or in high risk patients. ${ }^{89}$ These are patients with surgically inaccessible lesions, tandem lesions, contralateral ICA occlusion, those medically unfit with cardiac and/or respiratory problems, restenosis post-CEA due either to myointimal hyperplasia within 36 months of surgery or recurrent atherosclerosis thereafter, and radiation induced stenosis.

VERTEBRAL ARTERY ANGIOPLASTY AND STENTING The vertebral artery (VA) origin is difficult to access surgically and recognised surgical risks include the development of a Horner's, lymphatic injury, VA thrombosis, and laryngeal nerve injury. Endovascular treatment is therefore usually considered after failed medical treatment and performed as for CAS. The immediate goal is to obtain $<50 \%$ residual stenosis, no deficit, and resolution of symptoms. Technical success is high and estimated at $94-98 \%$. Procedure related complications are rare at $0-6 \%{ }^{90-92}$ and include stroke and arterial dissection. The main concern is restenosis at follow up with $>50 \%$ stenosis documented in $10-43 \%$ of patients treated. The higher rates of restenosis reported might relate to the patient population with more severe disease, longer follow up, and independent angiographic assessment. The vast majority of patients improve clinically, however. The 

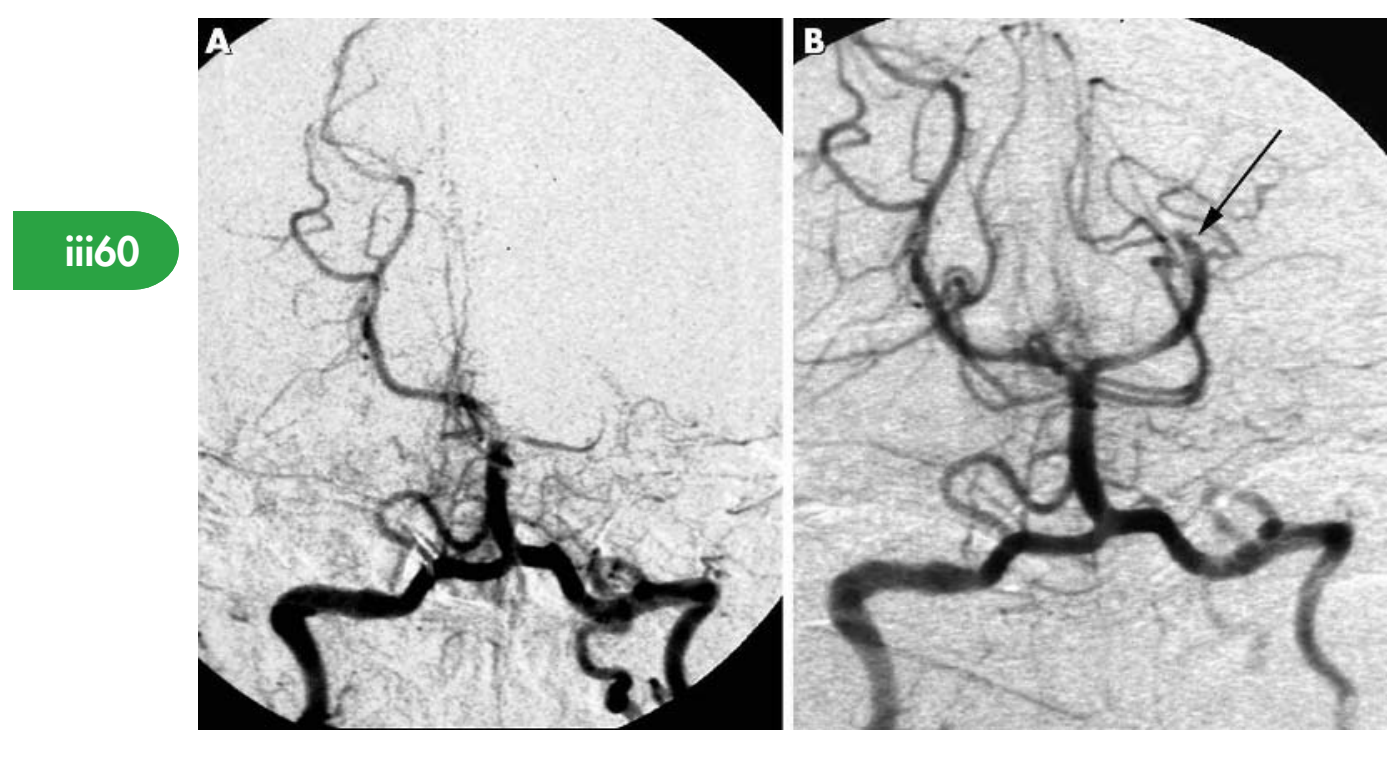

Figure 11 Local intra-arterial thrombolysis in a terminal basilar occlusion (A, B). Patient collapsed, Glasgow coma score 3. Cranial CT was normal but CTA and CTP (not shown) demonstrated a terminal basilar occlusion. Vertebral angiography (A) confirmed partial occlusion of the terminal basilar artery with no filling of the left posterior cerebral artery or left superior cerebellar arteries. $15 \mathrm{mg}$ rt-PA was delivered into the thrombus via a microcatheter placed up to the terminal basilar artery with a reopening of the terminal basilar, left superior cerebellar arteries and more proximal left posterior cerebral artery (B). Truncation of the posterior cerebral artery (distal P2) unfortunately remained (arrow) with a left sided cerebellar infarction. Patient made an excellent functional recovery. Figures courtesy of Dr Shawn Halpin.

severity of restenosis does not seem to correlate with symptoms and often more severe restenoses are asymptomatic, ${ }^{90}$ presumably because they reflect smooth myointimal hyperplasia and/or more effective collateralisation. Angioplasty alone, without stenting, is associated with a very high rate of restenosis. ${ }^{90} 91$

\section{HYPERACUTE ISCHAEMIC STROKE}

Intravenous recombinant tissue plasminogen activator (rtPA), given to selected patients within three hours of ictus, remains the only approved treatment for hyperacute ischaemic stroke (HIS). ${ }^{93}$ Unfortunately only $2-3 \%$ of the eligible population in the UK receive this treatment. Additionally, strict adherence to this time window precludes many patients who might benefit from thrombolytic treatment and includes those who are unlikely to benefit-for example, those with ICA and main trunk MCA (Ml) occlusions (if a proximal artery is occluded, insufficient intravenous drug reaches the thrombus) and those in whom the embolus has already dissipated (20-25\%). Severe strokes (implying a large relatively proximal clot) with little or no collateralisation usually do badly with intravenous rt-PA and risk ICH. ${ }^{93}{ }^{94}$ Alternative treatment should be considered in these cases.

HIS comprises a heterogeneous group of patients and the time window must vary on an individual basis. The time window and opportunity for treatment depends upon the site and extent of clot and the collaterals. Ideally, management should be individualised following investigation with cranial CT, CT angiography (CTA), and CT perfusion (CTP) studies (or MRI, MRA, diffusion weighted/perfusion weighted MRI (DWI/PWI)) to optimise and rationalise therapy. CTA/MRA will demonstrate the site and extent of clot and CTP/PWI/ DWI will help to differentiate already infarcted from ischaemic "at risk" but potentially viable tissue.

With a more distal branch occlusion and good collaterals, the time window is obviously longer. Conversely, if there is total occlusion of the M1 or proximal M2 which include the lenticulostriate arteries, the time window may be less than three hours (you have to allow some time for recanalisation). Lenticulostriate reperfusion after 4-5 hours of ischaemia is associated with an increased risk of haemorrhage. These are true end arteries, without a collateral circulation, supplying the basal ganglia which have a high metabolic rate.

Intra-arterial thrombolytic involves the direct infusion of thrombolytic into the occluding thrombus achieving higher local concentration of drug, lower systemic concentration, and fewer extracranial haemorrhagic complications. Faster and more complete recanalisation may be achieved, particularly with proximal MCA occlusions. This allows a longer time window of 3-6 hours or longer if perfusion studies are favourable. Cerebral angiography allows direct visualisation of the occluding thrombus and directly monitors thrombus dissolution.

Additionally, mechanical means may also be applied to disrupt the clot using the microguidewire and this may facilitate the action of the thrombolytic agent. Clot retrieval devices are now available which may actually extract the thrombus from the occluded artery, achieving reperfusion much more readily. Mechanical thrombolysis is obviously invaluable if the clot is resistant to intra-arterial rt-PA. Thrombus is often heterogeneous in nature and about 50\% are resistant. If thrombus is superimposed upon a stenosis, it may be necessary to undertake angioplasty or stent the lesion. Mechanical thrombolysis may also be considered if pharmacological thrombolysis is contraindicated.

Although intra-arterial techniques have distinct advantages, there are horrendous logistical problems. Intravenous thrombolysis obviously has the advantage of ease and rapidity of administration and avoids the disadvantages of intra-arterial treatment which include the inevitable additional time delays, risks of procedure (arterial embolisation, arterial perforation, haemorrhagic infarction, retroperitoneal haematoma, and groin haematoma). These risks are collectively estimated at 5\%. In addition, intra-arterial treatment requires specialist neurointerventional training.

There are a few small randomised trials ${ }^{95-97}$ comparing intra-arterial thrombolytic with placebo, within six hours of the ictus, and combination intra-arterial and intravenous treatment ${ }^{98-100}$ reporting encouraging results, but there are no randomised trials comparing intravenous and intra-arterial treatment. Current opinion suggests that intra-arterial treatment may be useful for large vessel occlusions and in those 

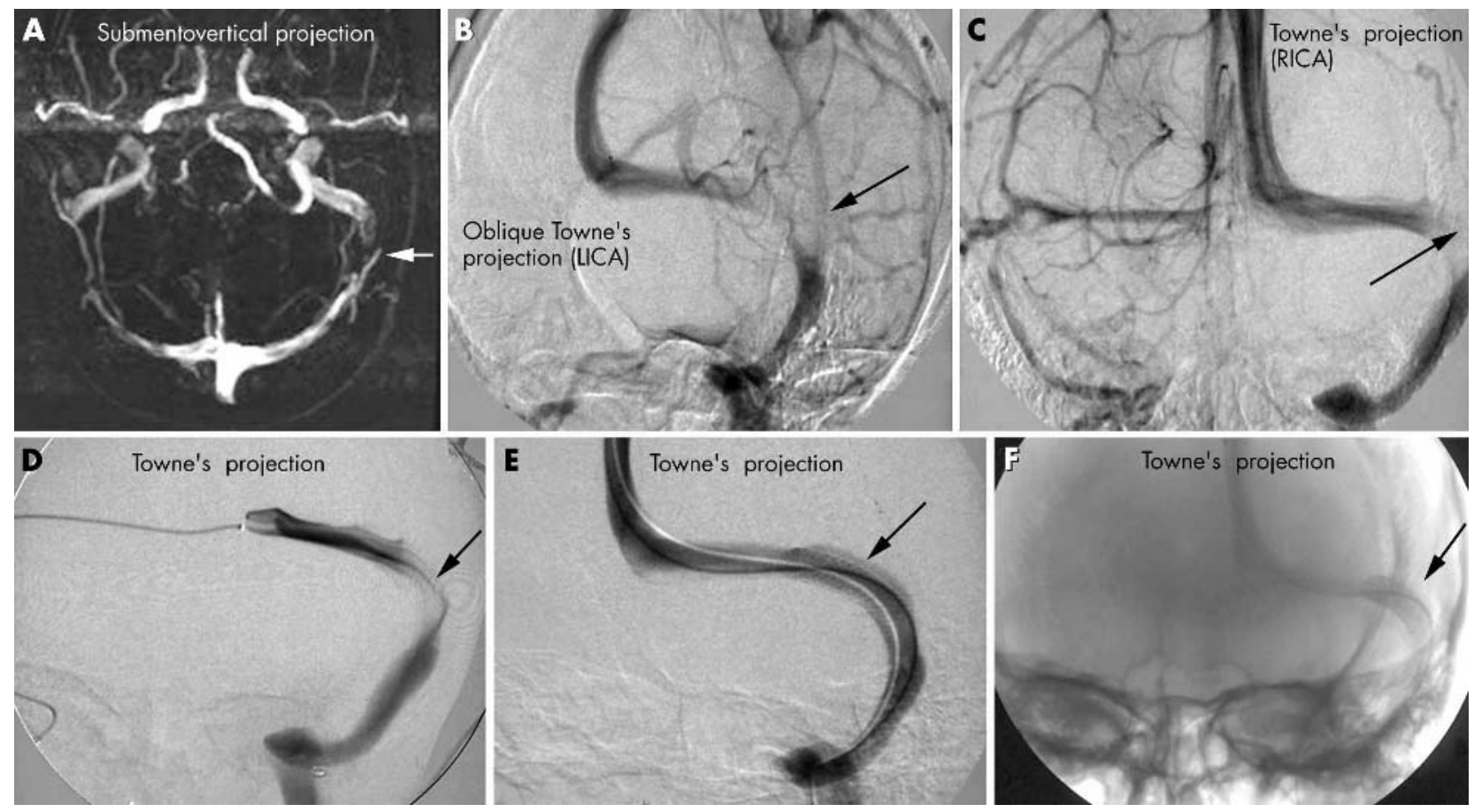

Figure 12 Sinus stenting in idiopathic intracranial hypertension (IIH) (A-F). A patient with IIH failed to respond to medical treatment and had deteriorating vision. Phase contrast MRV (A) demonstrated hypoplasia of the right transverse and sigmoid sinuses and a "flow gap" in the distal dominant left transverse sinus/sigmoid sinus junction (arrow). The "flow gap" indicated flow disturbance. Venous phase cerebral angiography (B, C) confirmed the MRV findings and demonstrated a "stenosis" at the site of the "flow gap" (arrow). Retrograde cerebral venography (D) from the right side, injecting at the torcula, again confirmed the "stenosis" (arrow) and pressure measurements demonstrated a significant pressure drop across it. A self expandable stainless steel stent (arrow) was deployed across the "stenosis" (E, F), curing the "stenosis" and pressure gradient, and resulted in a significant improvement in vision. Figures courtesy of Dr Nick Higgins.

presenting after 3-6 hours where DWI/PWI or CTP are favourable.

Vertebrobasilar occlusion is usually associated with a poor prognosis with overall mortality rates of $70-80 \%$. There are no randomised studies but many cases of thrombolysis are reported in the literature using local intra-arterial infusions of urokinase or rt-PA. ${ }^{101}$ Successful recanalisation, either partial or complete, may be achieved in $70 \%$ (fig 11 ), over a median infusion time of 120 minutes resulting in survival rates of $55-70 \%$. Survival rates in untreated or persistent occlusion is $0-10 \%$. All survivors in the untreated group are at least moderately disabled. Two thirds of those treated aggressively had good outcomes. Distal occlusions are likely due to emboli and not surprisingly are easier to lyse than proximal occlusions which are more likely the result of thrombus superimposed on atherosclerotic plaque. The latter often requires adjuvant treatment with angioplasty and/or stenting. Paradoxically, however, these may have generated collaterals so the time window is extended.

The precise time window is uncertain and therapeutic windows of up to 73 hours are reported. Coma or tetraparesis for several hours is indicative of a poor prognosis despite recanalisation. Signs of brain stem infarction on imaging is not always indicative of poor outcome.

\section{IDIOPATHIC INTRACRANIAL HYPERTENSION}

Cerebral venography and manometry have demonstrated venous hypertension in patients with idiopathic intracranial hypertension (IIH), occasionally secondary to raised central venous pressure but more often due to focal narrowing in the transverse sinuses bilaterally associated with a significant pressure gradient across the stenoses. In a significant number of patients (but not all), venous stenting has rendered these patients asymptomatic or improved with abolition of the pressure gradient ${ }^{102} 103$ and reduction in intracranial pressure. Balloon angioplasty is unsuccessful because of elastic recoil of the sinus wall post-procedure.

Some have shown ${ }^{104} 105$ that cerebrospinal fluid (CSF) aspiration in patients with IIH, during cerebral venography, eliminated or virtually eliminated pressure gradients in the transverse sinuses and intracranial hypertension. These concluded that the venous sinus deformity is secondary to the raised intracranial pressure but a rapid reduction in CSF pressure might be expected to dilate intracranial veins, increase their compliance and lower venous pressure whether the venous obstruction is primary or secondary.

Currently, it may only be concluded that venous outflow obstruction from transverse sinus stenoses is the primary cause of IIH in a proportion of patients only. Appropriate patient selection for stenting is critical and may be difficult, but even if the venous obstruction is secondary to raised intracranial pressure, stenting may still have a valuable role by reducing the superadded effects of venous hypertension.

MRI, MR venography (MRV), and even the venous phase of contrast cerebral angiography may not accurately demonstrate and assess the transverse sinus stenoses. Cerebral venography and manometry are the gold standard for diagnosis but this invasive investigation should be reserved for those who are not responding to medical treatment and in whom shunt procedures or optic nerve fenestrations are considered. Via a femoral vein, a guide catheter is retrogradely positioned in the jugular bulb and a microcatheter 
coaxially retrogradely manipulated through this into the venous sinuses and pressure measurements obtained.

General anaesthesia is required for stent deployment because the dura and sinuses are sensitive to pain. Stenting is achieved directly through a percutaneous jugular venous puncture. A guide catheter is manipulated into the transverse

sinus and a self expanding stent deployed across the stenosis (fig 12). The patient is heparinised during the procedure and for a variable period thereafter (centre dependent) and antiplatelet medication prescribed for a total of 3-6 months.

Serious complications have not yet been documented.

\section{CONCLUSION}

There has been enormous growth and development in neuroendovascular expertise and technology in recent years, and this expansion continues allowing increasingly safe and more effective ways to treat many intracranial and extracranial vascular lesions.

\section{REFERENCES}

1 ISAT Collaborative Group. International subarachnoid aneurysm trial (ISAT) of neurosurgical clipping versus endovascular coiling in 2143 patients with ruptured intracranial aneurysms: a randomised trial. Lancet 2002;360:1267-74.

2 ISAT Collaborative Group. The International subarachnoid aneurysm trial (ISAT): a multi-centre randomised trial comparing neurosurgical clipping with endovascular coiling in 2143 patients with ruptured intracranial aneurysms: overall effect on survival, dependency, seizures, rebleeding, subgroup analyses and frequency of angiographic aneurysm occlusion. Lancet (in press).

3 MacDonald RL, Wallace MC, Kestle JR. The role of angiography following aneurysm surgery. J Neurosurg 1993;79:826-32.

4 Hadjivassiliou $M$, Tooth $\mathrm{CL}$, Romanowski CA, et al. Aneurysmal SAH: cognitive outcome and structural damage after clipping or coiling. Neurology 2001;56:1672-7

5 Wiebers DO, Whisnant JP, Huston J, et al. Unruptured intracranial aneurysms: natural history, clinical outcome and risks of surgical and endovascular treatment. Lancet 2003;362:103-10.

6 Johnston SC, Dudley RA, Gress DR, et al. Surgical and endovascular treatment of unruptured aneurysms at university hospitals. Neurology 1999;52:1799-805.

7 Johnston SC, Wilson CB, Halbach VV, et al. Endovascular and surgical treatment of unruptured cerebral aneurysms: comparison of risks. Ann Neurology 2000;48:11-19.

8 Johnston SC, Zhao S, Dudley RA, et al. Treatment of unruptured cerebral aneurysms in California. Stroke 2001;32:597-605.

9 Nishioka H. Report on the cooperative study of intracranial aneurysms and subarachnoid haemorrhage. VIII, part 1: results of the treatment of intracranial aneurysms by occlusion of the carotid artery in the neck. J Neurosurg 1966;25:660-82.

10 Mathis JM, Barr JD, Jungreis CA, et al. Temporary balloon test occlusion of the internal carotid artery: experience in 500 cases. Am J Neuroradiol 1995; 16:749-54.

11 Stannard SC, Ahuja A, Guterman LR, et al. Balloon test occlusion of the internal carotid artery with hypotensive challenge. Am J Neuroradiol 1995; 16:1453-58.

12 Lorberboym M, Pandit N, Machac J, et al. Brain perfusion imaging during preoperative temporary balloon occlusion of the internal carotid artery. J Nucl Med 1996:37:415-19.

13 Schneweis S, Urbach H, Solymosi L, et al. Preoperative risk assessment for carotid occlusion by transcranial Doppler ultrasound. J Neurol Neurosurg Psychiatry 1997;62:485-9.

14 De Vries EJ, Sekhar LN, Horton JA, et al. A new method to predict safe resection of the internal carotid artery. Laryngoscope 1990;100:85-8.

15 Gonzalez CF, Moret J. Balloon occlusion of the carotid artery prior to surgery for neck tumours. Am J Neuroradiol 1990;11:649-52.

16 Larson JL, Tew JM, Tomsick TA, et al. Treatment of aneurysms of the internal carotid artery by intravascular balloon occlusion: long term follow up of 58 patients. Neurosurgery 1995;36:23-30.

17 Erba SM, Horton JA, Latchaw RE, et al. Balloon test occlusion of the internal carotid artery with stable/CT cerebral blood flow imaging. Am J Neuroradiol 1988;9:533-8.

18 Eckard DA, Purdy PD, Bonte FJ. Temporary balloon occlusion of the carotid artery combined with brain blood flow imaging as a test to predict tolerance prior to permanent carotid sacrifice. Am J Neuroradiol 1992;13:1565-9.

19 Eskridge JM. Xenon-enhanced CT: past and present. Am J Neuroradiol 1994; 15:845-6.

20 Origitano TC, Al-Mefty $\mathrm{O}$, Leonetti JP, et al. Vascular considerations and complications in cranial base surgery. Neurosurgery 1994;35:351-63.

21 Mclvor NP, Willinsky RA, Terbrugge KG, et al. Validity of test occlusion prior to internal carotid artery sacrifice. Head and Neck 1994;16:11-16.
22 Linksey $M E$, Jungreis $C A$, Yonas $\mathrm{H}$, et al. Stroke risk after abrupt internal carotid artery sacrifice: accuracy of preoperative assessment with balloon test occlusion and stable xenon-enhanced CT. Am J Neuroradiol 1994; 15:829-43.

23 Clark WC, Ray MW. Contralateral intracranial aneurysm formation as a late complication of carotid ligation. Surg Neurol 1982;18:458-62.

24 Dyste GW, Beck DW. De novo aneurysm formation following carotid ligation: case report and review of the literature. Neurosurgery 1989;24:88-92.

25 Poppen JL. Specific treatment of intracranial aneurysms. Experience with 143 surgically treated patients. J Neurosurg 1951;8:75-102.

26 Faria MA Jr, Fleischer AS, Spector RH. Bilateral giant intracavernous carotid aneurysms treated by bilateral carotid ligation. Surg Neurol 1980; 14:207-10.

27 Batjer H, Mickey B. Enlargement and rupture of distal basilar aneurysm after iatrogenic carotid occlusion. Neurosurgery 1987;20:624-8.

28 Timperman PE, Tomsick TA, Tew JM, et al. Aneurysm formation after carotid occlusion. Am J Neuroradiol 1995; 16:329-31.

29 Linksey ME, Sekhar LN, Horton JA, et al. Aneurysms of the intracavernous carotid artery: a multidisciplinary approach to treatment. J Neurosurg $1991 ; 75: 525-34$.

30 Fox AJ, Vinuela F, Pelz PM, et al. Use of detachable balloons for proximal artery occlusion in the treatment of unclippable cerebral aneurysms. J Neurosurg 1987;66:40-6.

31 Berenstein A, Ransohoff J, Kupersmith M, et al. Transvascular treatment of giant aneurysms of the cavernous carotid and vertebral arteries. Functional investigation and embolization. Surg Neurol 1984;21:3-12.

32 Molyneux AJ, Cerkirge S, Saatchi I, et al. Cerebral aneurysm multicenter European Onyx (CAMEO) trial: results of a prospective observational study in 20 European centres. Am J Neuroradiol 2004;25:39-51.

33 Crawford PM, West CR, Chadwick DW, et al. Arteriovenous malformations of the brain: natural history in unoperated patients. J Neurol Neurosurg Psychiatry 1986;49:1-10.

34 Deruty R, Pelissu-Guyotat I, Morel C, et al. Reflections on the management of cerebral arteriovenous malformations. Surg Neurol 1998;50:245-56.

35 Mast H, Young WL, Koennecke, et al. Risk of spontaneous hemorrhage after diagnosis of cerebral arteriovenous malformations. Lancet 1997;350: 1065-8.

36 Redekop G, Terbrugge K, Montanera W, et al. Arterial aneurysms associated with cerebral arteriovenous malformations: classification, incidence and risk of haemorrhage. J Neurosurg 1998;89:539-46.

37 Pollock BE, Flickinger JC, Lunsford LD, ef al. Factors that predict bleeding risk of cerebral arteriovenous malformations. Stroke 1996;27:1-6.

38 Frizzel RT, Fisher WS. Cure, morbidity and mortality associated with embolization of brain arteriovenous malformations: a review of 1246 patients in 32 series over a 35 -year period. Neurosurgery 1995;37:1031-40.

39 Gruber A, Mazal PR, Bavinski G, et al. Repermeation of partially embolised cerebral arteriovenous malformations: a clinical, radiologic and histologic study. Am J Neuroradiol 1996;17:1323-31.

40 Gobin YP, Laurent A, Merienne L, et al. Treatment of brain arteriovenous malformations by embolization and radiosurgery. I Neurosurg 1996;85:19-28

41 Fournier D, Terbrugge KG, Willinsky R, et al. Endovascular treatment of intracerebral arteriovenous malformations: experience in 49 cases. J Neurosurg 1991;75:228-33.

42 Richling B, Killer M. Endovascular management of patients with cerebral arteriovenous malformations. Neurosurg Clin North America 2000;11:123-45.

43 Taylor CL, Dutton K, Rappard G, et al. Complications of preoperative embolization of cerebral arteriovenous malformations. J Neurosurg 2004; 100:810-12.

44 Macpherson P. The value of pre-operative embolisation of meningioma estimated subjectively and objectively. Neuroradiology 1991;33:334-7.

45 Dean BL, Flom RA, Wallace RC, et al. Efficacy of endovascular treatment of meningiomas: evaluation with matched samples. Am J Neuroradiol 1994; 15:1675-80.

46 Wakhloo AK, Juengling FD, Delthoven VV. Extended preoperative polyviny alcohol microembolization of intracranial meningiomas: assessment of two embolization techniques. Am J Neuroradiol 1993;14:571-82.

47 Motozaki T, Otuka S, Sato S, et al. Preoperative embolization with gelfoam powder for intracranial meningioma causing unusual peritumoural hemorrhage-with reference to the mechanism of hemorrhage. No Shinkei Geka 1987;15:95-101.

48 Kallmes DF, Evans AJ, Kaptain GJ, et al. Hemorrhagic complications in embolization of a meningioma: case report and review of the literature. Neuroradiology 1997;39:877-80.

49 George B, Casasco A, Deffrennes D, et al. Intratumoral embolization of intracranial and extracranial tumours; technical note. Neurosurgery 1994;35:771-4

50 Casasco A, Herbreteau D, Houdart E, et al. Devascularisation of craniofacia tumours by percutaneous puncture. Am J Neuroradiol 1994;15:1233-9.

51 Higashida RT, Halbach VV, Tsai FY, et al. Interventional neurovascular treatment of traumatic carotid and vertebral artery lesions: results in 234 cases. Am J Radiol 1989;153:577-83.

52 Debrun G. Management of traumatic carotid-cavernous fistulas. In: Vinuela F, et al, eds. Interventional neuroradiology: endovascular therapy of the central nervous system. New York: Raven Press, 1992:107-12.

53 Lewis Al, Tomsick TA, Tew JM, et al. Long-term results in direct carotidcavernous fistulas after treatment with detachable balloons. J Neurosurg 1996:84:400-4. 
54 Lewis Al, Tomsick TA, Tew JM. Management of 100 consecutive direct carotid-cavernous fistulas: results of treatment with detachable balloons. Neurosurgery 1995;36:239-45.

55 Halbach VV, Higashida RT, Hieshima GB, et al. Dural fistulas involving the cavernous sinus: results of treatment in 30 patients. Radiology 1987:163:437-42.

56 Picard L, Bracard S, Mallet J, et al. Spontaneous dural arteriovenous fistulas. Seminars in Interventional Radiology 1987;4:219-40.

57 Turiman $F$, Bascoulergue $Y$, Rosenberg $M$, et al. Dural fistulae of the cavernous sinus treated by embolization. J Neuroradiol 1992;19:256-70.

58 Halbach VV, Higashida RT, Hieshima GB, et al. Endovascular therapy of dural fistulas. In: Vinuela F, et al, eds. Interventional neuroradiology: endovascular therapy of the central nervous system. New York: Raven Press, 1992:29-50.

59 Newton TH, Cronqvist S. Involvement of the dural arteries in intracranial arteriovenous malformations. Radiology 1969;93:1071-8.

60 Lucas CP, Zabramski JM, Spetzler RF, et al. Treatment for intracranial dura arteriovenous malformations: a meta-analysis from the English literature. Neurosurgery 1997;40:1119-32.

61 Cognard C, Gobin YP, Pierot L, et al. Cerebral dural arteriovenous fistulas: clinical and angiographic correlation with a revised classification of venous drainage. Radiology 1995; 194:671-80.

62 Roy D, Raymond J. The role of transvenous embolization in the treatment of intracranial dural arteriovenous fistulas. Neurosurgery 1997;40:1133-44.

63 Gobin YP, Houdart E, Rogopoulos A, et al. Percutaneous transvenous embolization through the thrombosed sinus in transverse sinus dural fistula. Am J Neuroradiol 1993; 14:1102-5.

64 Endo S, Kuwayama N, Takaku A, et al. Direct packing of the isolated sinus in patients with dural arteriovenous fistulas of the transverse-sigmoid sinus. J Neurosurg 1998;88:449-56.

65 Castaigne $\mathrm{P}$, LaPlane D, Bousser MP. Superior sagittal sinus thrombosis. Arch Neurol 1977;34:788-9.

66 DiRocco C, lannelli A, Leone G, et al. Heparin-urokinase treatment in aseptic dural sinus thrombosis. Arch Neurol 1981;38:431-5.

67 Vines FS, Davis DO. Clinical-radiological correlation in cerebral venous occlusive disease. Radiology 1971;98:9-22

68 Gettelfinger DM, Kokmen E. Superior sagittal sinus thrombosis. Arch Neurol 1977;34:2-6.

69 Gates PC, Barnet HJM. Venous disease: cortical veins and sinuses. In: Barnett HJM, Mohr JP, Stein B, Yatsy FM, eds. Stroke: pathophysiology, diagnosis and management. New York: Churchill-Livingstone, 1986:731-46.

70 Nagatomo Y, Yaneka K, Kamezaki T, et al. Recovery from primary deep cerebral venous sinus thrombosis with recanalisation. Neuroradiology 1995; 37:645-8.

71 Scott JA, Pascuzzi RM, Hall PV, et al. Treatment of dural sinus thrombosis with local urokinase infusion. J Neurosurg 1988;68:284-7.

72 Novak Z, Coldwell DM, Brega KE. Selective infusion of urokinase and thrombectomy in the treatment of acute cerebral sinus thrombosis. Am J Neuroradiol 2000;21:143-5.

73 Chaloupka JC, Mangla S, Huddle DC. Use of mechanical thrombolysis via microballoon percutaneous angioplasty for the treatment of acute dural sinus thrombosis. Neurosurgery 1999:45:650-7.

74 Genton E, Wolf PS. Urokinase therapy in pulmonary thromboembolism. Am Heart J 1968;76:628-37

75 Frey JL, Munro GJ, McDougall CG, et al. Cerebral venous thrombosis. Combined intrathrombus rtTPA and intravenous heparin. Stroke 1999:30:489-94

76 Opatowsky MJ, Morris PP, Regan JD, et al. Rapid thrombectomy of superio sagittal sinus and transverse sinus thrombosis with a rheolytic catheter device. Am J Neuroradiol 1999;20:414-17.

77 Dowd CF, Malek AM, Phatouros CC, et al. Application of a rheolytic thrombectomy device in the treatment of dural sinus thrombosis: a new technique. Am J Neuroradiol 1999;20:568-70.

78 Scarrow AM, Williams RL, Jungreis CA, et al. Removal of a thrombus from the sigmoid and transverse sinuses with a rheolytic thrombectomy catheter. Am J Neuroradiol 1999:20:1467-9.

79 Chow K, Gobin P, Saver J, et al. Endovascular treatment of dural sinus thrombosis with rheolytic thrombectomy and intraarterial thrombolysis. Stroke 2000;31:1420-5

80 Baker MD, Opatowsky MJ, Wilson JA, et al. Rheolytic catheter and thrombolysis of dural sinus thrombosis: a case series. Neurosurgery $2001 ; 48: 487-94$
81 Gomez CR, Misra VK, Tulyapronchote R, et al. Emergency endovascular treatment of cerebral sinus thrombosis with a rheolytic catheter device. J Neuroimag 2000;10:177-80.

82 Malek AM, Higashida RT, Balousek PA, et al. Endovascular recanalisation with balloon angioplasty and stenting of an occluded occipital sinus in the treatment of venous hypertension. Neurosurgery 1999;44:896-901.

83 Murphy KJ, Gailloud P, Venbrux A, et al. Endovascular treatment of a grade IV dural arteriovenous fistula by sinus recanalisation by angioplasty and sten placement. Neurosurgery 2000;46:497-500.

84 Chaturvedi S, Aggarwal R, Murugappan A. Results of carotid endartectomy with prospective neurologist follow-up. Neurology 2000;55:769-72.

85 CAVATAS Investigators. Endovascular versus surgical treatment in patients with carotid stenosis in the carotid and vertebral artery transluminal angioplasty study (CAVATAS): a randomized trial. Lancet 2001;357:1729-37.

$86 \mathrm{McC}$ abe DJH, Pereira AC, Clifton AC, et al. Restenosis after carotid angioplasty, stenting or endarterectomy in the carotid and vertebral artery transluminal angioplasty study (CAVATAS). Stroke 2005;36:281-6.

87 Wholey MH, Al-Mubarek N. Updated review of the global carotid artery stent registry. Catheter Cardiovasc Interv 2003;60:259-66.

88 Wholey MH, Jarmolowski CR, Wholey M. Carotid artery stent placement ready for prime time? J Vasc Interv Radiol 2003;14:1-10.

89 Coward LJ, Featherstone RL, Brown MM. Percutaneous transluminal angioplasty and stenting for carotid artery stenosis. Cochrane Database Syst Rev 2004; 2: CD000515.

90 Albuqueque FC, Fiorella $D$, Han $P$, et al. A reappraisal of angioplasty and stenting for the treatment of vertebral artery origin stenosis. Neurosurgery 2003;53:607-16.

91 Cloud GC, Crawley F, Clifton A, et al. Vertebral artery origin and primary stenting: safety and restenosis rates in a prospective series. J Neurol Neurosurg Psychiatry 2003;74:586-90.

92 Wehman JC, Hanel RA, Guidot CA, et al. Atherosclerotic occlusive extracranial vertebral artery disease: indications for intervention, endovascular techniques, short term and long term results. J Interventional Cardiol 2004; 17:219-32

93 The National Institute of Neurological Disorders and Stroke rt-PA Stroke Study Group. Tissue plasminogen activator for acute ischaemic stroke. N Engl J Med 1995;333:1581-7.

94 Albers GW, Bates VE, Clark WM, et al. Intravenous tissue-type plasminogen activator for treatment of acute stroke. JAMA 2000;283:1 145-50.

95 Del Zoppo GJ, Higashida RT, Furlan AJ, et al. PROACT: a phase II randomized trial of recombinant pro-urokinase by direct arterial delivery in acute middle cerebral artery stroke. Stroke 1998;29:4-11.

96 Furlan A, Higashida R, Wechsler L, et al. Intra-arterial prourokinase for acute ischaemic stroke: the PROACT II study - a randomised control study in acute cerebral thromboembolism. JAMA 1999;282:2003-11.

97 Lisboa RC, Jovanovic BD, Alberts MJ. Analysis of the safety and efficacy of intra-arterial thrombolytic therapy in ischaemic stroke. Stroke 2002;33:2866-71.

98 Lewandowski CA, Frankel M, Tomsick TA, et al. Combined intravenous and intra-arterial therapy of acute ischaemic stroke. Emergency management of stroke (EMS) bridging trial. Stroke 1999;30:2598-605.

99 Keris V, Rudnicka S, Vorona V, et al. Combined intra-arterial/intravenous thrombolysis for acute ischaemic stroke. Am J Neuroradiol 2001;22:352-8.

100 Surez JI, Zaidat OO, Sunshine JL, et al. Endovascular administration after intravenous infusion of thrombolytic agents for the treatment of patients with acute ischaemic strokes. Neurosurgery 2002;50:251-60.

$101 \mathrm{Ng}$ PP, Higashida RT, Cullen SP, et al. Intraarterial thrombolysis trials in acute ischaemic stroke. J Vasc Interv Radiology 2004;15:S77-85.

102 Owler BK, Parker G, Halmagyl GM, et al. Pseudotumour cerebri syndrome: venous sinus obstruction and its treatment with stent placement. J Neurosurg 2003;98:1045-55.

103 Higgins JNP, Cousins C, Owler BK, et al. Idiopathic intracranial hypertension: 12 cases treated by venous sinus stenting. J Neurol Neurosurg Psychiatry 2003;74:1662-6.

104 King JO, Mitchell PJ, Thomson KR, et al. Manometry combined with cervical puncture in idiopathic intracranial hypertension. Neurology 2002;58:26-30.

105 Baryshnik DB, Farb RI. Changes in the appearance of venous sinuses after treatment of disordered intracranial pressure. Neurology 2004;62:1445-6. 